\title{
Sub-micro droplet reactors: Green synthesis of Li3V04 anode materials for lithium ion batteries
}

\section{Tran Ha}

Hanyang University

\section{Ngoc Hung Vu}

Phenikaa University

\section{Hyunwoo Ha}

Chungnam National University https://orcid.org/0000-0002-3874-8669

\section{Joonhee Moon}

Korea Basic Science Institute

\section{Hyun You Kim}

Chungnam National University https://orcid.org/0000-0001-8105-1640

Won Bin Im ( $D$ imwonbin@hanyang.ac.kr)

Hanyang University https://orcid.org/0000-0003-2473-4714

\section{Article}

Keywords: Acid-base Reactions, Ca-doping, Crystal Growth, Pseudocapacitance

Posted Date: October 13th, 2020

DOI: https://doi.org/10.21203/rs.3.rs-78893/v1

License: (c) (1) This work is licensed under a Creative Commons Attribution 4.0 International License. Read Full License

Version of Record: A version of this preprint was published at Nature Communications on May 25th, 2021. See the published version at https://doi.org/10.1038/s41467-021-23366-8. 


\section{Sub-micro droplet reactors: Green synthesis of}

\section{$\mathrm{Li}_{3} \mathrm{VO}_{4}$ anode materials for lithium ion batteries}

Ha Tran Huu ${ }^{1}$, Ngoc Hung Vu²,3 Hyunwoo $\mathrm{Ha}^{4}$, Joonhee Moon ${ }^{5}$, Hyun You Kim4, and Won Bin $\operatorname{Im}^{1, *}$

${ }^{I}$ Division of Materials Science and Engineering, Hanyang University, 222, Wangsimni-ro, Seongdong-gu, Seoul, 04763, Republic of Korea

${ }^{2}$ Falcuty of Biotechnology, Chemistry and Environmental Engineering, Phenikaa University,

Hanoi 10000, Vietnam

${ }^{3}$ Phenikaa Research and Technology Institute, A\&A Green Phoenix Group, 167 Hoang Ngan, Hanoi 10000, Vietnam

${ }^{4}$ Department of Materials Science and Engineering, Chungnam National, University, Daejeon, 34134, Korea

${ }^{5}$ Advanced Nano-Surface Research Group, Korea Basic Science Institute, Daejeon 34133, Republic of Korea

${ }^{*}$ To whom correspondence should be addressed.

Tel: +82-2-2220-0404

E-mail: imwonbin@hanyang.ac.kr 


\begin{abstract}
A new green-chemistry strategy, based on modified solid-state reaction with the addition of water vapor to accelerate acid-base reactions $(\mathrm{ABR})$ at low temperature, was developed along with Cadoping to synthesize electrode material for lithium-ion batteries. The new method which helps in control the particles size and saving energy in synthesis has been developed. To explain this process, we proposed a mechanism in which water droplets play a key role as sub-micro reactors, calculated as few tens of nanometers, to ensure proper reaction conditions and confine crystal growth to nano-dimensions. The synergic effect of the proposed ABR method and Ca-doping is discussed to further explain the increase in the specific surface area and electrochemical performance of the anode material. The optimized material, Ca-doped $\mathrm{Li}_{3} \mathrm{VO}_{4}$, delivers a superior specific capacity of $543.1 \mathrm{mAh} \cdot \mathrm{g}^{-1}$ after 200 cycles at a current density of $100 \mathrm{~mA} \cdot \mathrm{g}^{-1}$, which could be attributed to the contribution of pseudocapacitance.
\end{abstract}


Since the first commercial products of Sony in 1991, lithium ion batteries (LIBs) and other potentially replaceable metal-ion storage sources such as $\mathrm{Na}^{+}$ion, ${ }^{1,2} \mathrm{Mg}^{2+}$ ion, ${ }^{3,4}$ and $\mathrm{Al}^{3+}$ ion $^{5}$ batteries, have attracted much attention for developing systems with high energy density, low cost, environmental benignity, and high safety. ${ }^{6}$ Among the various methods investigated for the synthesis methods of LIBs electrode, the solid-state reaction (SSR) is a popular routes as it is simple, does not require any solvent, and can be easily scaled up to the industrial level. However, this method does have several weaknesses. Firstly, due to the low ionic diffusion in the solid state, SSR kinetics at room temperature are so low that the reaction cannot occur even when the ambient condition are thermodynamically favorable. Therefore, SSR synthesis always requires high temperature for long periods of time which implies huge energy consumption. Secondly, because the reaction can occur only at the solid/solid or gas/solid interfaces, the core may remain unreacted. Thus, it is difficult to achieve high uniformity and unwanted intermediate phases may be formed. Finally, treatment at high temperatures for long time could lead to the agglomeration of particles with uncontrollable morphologies. However, the particle size is still so large that it could lead to poor electrochemical properties in the intercalated materials. Hence, it is necessary to investigate alternative strategies that satisfy these economical and environmental requirements, a new strategy has been developed to overcome limitations of SSR., ${ }^{7,9}$

In particular, the acid-base reaction ( $\mathrm{ABR}$ ) based process, which is carried out in the solid state in the humid atmosphere at low temperatures (below the boiling point of water). The addition of water vapor, formed by the evaporation of water at $80^{\circ} \mathrm{C}$, is the key factor in this modified pathway. In addition, the droplets formed during water condensation can not only serve as sub-micro droplet reactor in which the main ABR performed, but also confine the particle size and control morphology of the final materials. Based on this concept, we synthesized numerous 
materials as electrodes for LIBs or sodium-ion batteries (SIBs). In this investigation, a modification strategy for one such material, $\mathrm{Li}_{3} \mathrm{VO}_{4}$ is described. Inspire of its inherent advantages, such as a higher theoretical capacity $\left(591 \mathrm{mAh} \cdot \mathrm{g}^{-1}\right)$ than graphite, low and safe voltage plateaus, and low cost, the actual utilization of $\mathrm{Li}_{3} \mathrm{VO}_{4}$ is restricted by drawbacks including large particle size and low electronic conductivity. ${ }^{10,11,12}$ Therefore, many studies have been undertaken to overcome the aforementioned limitations using two strategies: i) increasing its electronic conductivity (via doping, ${ }^{13,14,15,16}$ composite fabrication with graphene, ${ }^{17,18,19}$ carbon nanotube, ${ }^{20}$ or carbon coating, ${ }^{21,22,23,24}$ etc.) and ii) reducing the particle size and controlling morphology. In this study, for the first time, we demonstrate the application of ABR to fabricate $\mathrm{Li}_{3} \mathrm{VO}_{4}$ and control its morphology and particles size. In addition, a green combination of the ABR strategy and $\mathrm{Ca}$ doping was employed to enhance the electrochemical properties of $\mathrm{Li}_{3} \mathrm{VO}_{4}$. Otherwise, reaction mechanism is proposed to estimate the confined size of the droplet reactors in nanoscale and illuminate the doping effect on modification surface area of doped samples.

\section{Results and discussion}

As shown in X-ray diffraction of Figure 1a, at low contents of calcium (1\% and 3\%), the XRD profiles indicate a single orthorhombic phase of $\mathrm{Li}_{3} \mathrm{VO}_{4}$, indicating the successful substitution of $\mathrm{Ca}^{2+}$ into $\mathrm{Li}^{+}$sites without the formation of an impurity phase. Nevertheless, at $5 \%$ Ca-doping, the appearance of an unexpected peak, at $2 \theta \sim 30.67^{\circ}$ (plus mark), indicates the formation of a new phase, $\mathrm{Ca}_{7} \mathrm{~V}_{4} \mathrm{O}_{17}$, in small amounts. Meanwhile, the substitution of larger radius ion at Li site could lead to the expansion of inter-planar $d$ spacing as illustrated by the shift of (200) peak to lower $2 \theta$ angles (expansion of Figure 1a). ${ }^{14}$ Rietveld refinement results performed on two representative samples, $0 \mathrm{LCVO}-\mathrm{ABR}$ and $3 \mathrm{LCVO}-\mathrm{ABR}(x=0,1,3,5$ in $x \mathrm{LCVO}$ equals to $\% \mathrm{Ca}$ introduced in samples) are displayed in Figure 1b,c, and S1-3; the calculated lattice 
parameters are shown in Table 1, and S1 while the structural parameters are listed in Table 2 and S2-4. An illustration of the crystal structure of the orthorhombic phase with a space group of Pnm2 1 constructing from two types of tetrahedral sites of $\mathrm{LiO}_{4}$ and $\mathrm{VO}_{4}$, is shown in Figure $1 \mathrm{~d}$. It is evident that $\mathrm{Ca}^{2+}$ ions prefer to replace $\mathrm{Li}^{+}$ions at $2 a$ and $4 b$ sites rather than $\mathrm{V}$ site owing to the fact that the ionic radius of $\mathrm{Ca}^{2+}(1.0 \AA$, coordination number, $\mathrm{CN}=6)$ is much larger than that of $\mathrm{V}^{5+}(0.355 \AA, \mathrm{CN}=4)$ but closer to that of $\mathrm{Li}^{+}(0.59 \AA, \mathrm{CN}=4)$. Moreover, the disparity in valence between $\mathrm{V}^{5+}$ and $\mathrm{Ca}^{2+}$ is larger than that between $\mathrm{Li}^{+}$and $\mathrm{Ca}^{2+}$. Therefore, it is more propitious for $\mathrm{Ca}^{2+}$ ions to occupy Li-sites to form a non-impurity phase. ${ }^{13}$ Furthermore, the data in Table 1 and Figure 1e indicates that the $a, b$, and $c$ values and unit cell volume of Ca-doped samples increase slightly as the $\mathrm{Ca}^{2+}$ dopant increases, thus confirming our conclusion of crystalline lattice enlargement, which is beneficial for enhancing $\mathrm{Li}^{+}$ion flexibility and rate capacity. ${ }^{13,25}$ The formation of oxygen vacancies $\left(V_{0}\right)$ to accommodate lattice strain due to the inconsistent of $\mathrm{CN}$ between $\mathrm{Ca}^{2+}$ and $\mathrm{Li}^{+}$species can be determined by density functional theory (DFT) calculation; such $V_{O}$ formation enhances ionic diffusion in doped samples.

For morphology investigation, the field-emission scanning electron microscopy (FESEM) image of 0LCVO-SSR (Figure S4a) exhibits a giant particles with dimension greater than $5 \mu \mathrm{m}$ with a smooth morphology, caused by particle aggregation during sintering at high temperatures. ${ }^{25,26}$ However, after doping with a small amount of Ca, 3LCVO-SSR (Figure S4b) exhibited much smaller particles with rough surfaces. The reduction in the particle size of the doped samples could be clarified by the variation in the surface energy or lattice strain, which limits the crystal from further growth due to the occupation of hetero-atoms. ${ }^{27,28}$ Meanwhile, in the ABR case, the SEM image in Figure 2a illustrates aggregation of rough and variegated particles. The few-ten-nanometer dimension demonstrates that the particle size was significantly 
reduced in new method. Ca-doped samples obtained via the same reaction exhibit a similar morphology (as shown in Figure 2b). However, the presence of $\mathrm{Ca}^{2+}$ ions significantly altered the surface, as observed by the formation of "open pore" and a strongly non-uniform arrangement of primary particles (as shown in the transmission electron microscopy (TEM) images in Figure 2c). While the edge surface of 0LCVO-ABR (Figure S4d) was tightly constructed with very less pores, the surface of 3LCVO-ABR (Figure 2c) clearly exhibited a the high porosity with a loose stacking of nanoparticles. In addition, the high-resolution TEM (HR-TEM, Figure 2d) images shows that the $d$-spacing of the (100) plane of 3LCVO-ABR is $5.61 \AA$, which is larger than the theoretical value of $5.44 \AA$. This could be attributed to the larger ionic radius of $\mathrm{Ca}^{2+}$ ion than that of $\mathrm{Li}^{+}$ion which is consistent with our XRD observation. Further crystal lattice information was confirmed by selected area electron diffraction (SAED, Figure 2e).

To clarify the mechanism of particle size control via $\mathrm{ABR}$, in situ Raman analysis was conducted during the preparation of pristine $\mathrm{Li}_{3} \mathrm{VO}_{4}$. The obtained data is shown in Figure $\mathrm{S} 5$, in which images in the first and second lines show photographs of sample surface under green and white light. When observed by the naked eye (Figure S5a), it is clear that the initial LiOH and formed $\mathrm{Li}_{3} \mathrm{VO}_{4}$ are white and crystalline, and the yellow particles can be attributed to $\mathrm{V}_{2} \mathrm{O}_{5}$. Under green laser light (Figure S5b), however, the color of the substances changed distinctly with $\mathrm{LiOH}$ turning black, while $\mathrm{V}_{2} \mathrm{O}_{5}$ reflected green light and the product could be detected in the blue region. For clarifying a reasonable mechanism, in situ Raman analysis was conducted on three positions at specific time intervals throughout the reaction period. The initial position 1 is ascribed to $\mathrm{V}_{2} \mathrm{O}_{5}$, position 2 is the location of $\mathrm{LiOH}$ particles, and the remaining is the contacting region between the two species. At the beginning of the reaction, $\mathrm{LiOH}$ was characterized by an intense peak located at $1090 \mathrm{~cm}^{-129}$ in the spectrum generated at position 2. Meanwhile, the Raman peaks at 
position 1 centered at 144 , and $193 \mathrm{~cm}^{-1}$ are attributed to the vibration of the lattice while peaks at 283, 408 and $993 \mathrm{~cm}^{-1}$ can be indexed to the bending and stretching mode of $\mathrm{V}=\mathrm{O}$ bonds. ${ }^{30}$ After 90 min of reaction, the peaks' intensity at position 1 decreased and this effect might be attributed to the surrounding of water layer as well as dissolving consumption by droplet. Whereas, the spectrum generated at position 2 contains peaks related to $\mathrm{LiOH}$ as well as new peaks in the range of $250-500$ and $750-900 \mathrm{~cm}^{-1}$ corresponding to the formation of $\mathrm{Li}_{3} \mathrm{VO}_{4}$, indicating the higher reaction rate of these areas. This in turn can be ascribed to the high solubility of $\mathrm{LiOH} .{ }^{31,19,18}$ Similar signals could be observed in the spectrum at position 3, demonstrating that the formation of $\mathrm{Li}_{3} \mathrm{VO}_{4}$ could occur at any delocalized position due to the mobility of the droplet-reactor. The low solubility of $\mathrm{V}_{2} \mathrm{O}_{5}$ in water inhibits the synthesis reaction, which is confirmed by the spectrum at position 1, in which only the peaks of V-precursor were remaining. In contrast, in other places, the formation of the final product was almost complete after 270 min. Based on this data, a hypothesized mechanism may be proposed for the ABR. As simulated in Figure 2f, firstly, the precursor particles is surrounded by water molecules, and hence, they exhibit different behaviors depending on their solubility. Owing to the low water solubility of $\mathrm{V}_{2} \mathrm{O}_{5}$, water vapor is only absorbed on these particles and make their surfaces more acidic. In contrast, $\mathrm{LiOH}$, which exhibits high solubility in water, may be diluted in water droplets and easily transferred to other places, especially acidic V-surfaces, to perform the main acid-base reaction. After moving to the surface of $\mathrm{V}_{2} \mathrm{O}_{5}$, the basic environment of the $\mathrm{LiOH}$ droplet dissolves the vanadium precursor to form nucleating $\mathrm{Li}_{3} \mathrm{VO}_{4}$ species, which are more water soluble. At the limit of solubility of $\mathrm{Li}_{3} \mathrm{VO}_{4}$, they crystallize to form solid $\mathrm{Li}_{3} \mathrm{VO}_{4}$ while water evaporates back to begin another cycle. However, the size of particles growing on nucleating groups is confined by water vapor droplets to several tens of nanometers. The detailed calculation of water droplet size is presented in the Supporting 
Information (SI). Accordingly, the maximum radius to which the droplet can grow can be calculated using the Equation S1, according to which, at a saturation degree (S) of 0.872, the maximum radius to which the droplet can grow is in the range of $25.56 \mathrm{~nm}$ (for a total number of moles of solute $\left.\mathrm{N}_{\mathrm{s}}=10^{-18} \mathrm{~mol}\right)$ to $2.58 \mu \mathrm{m}\left(\mathrm{N}_{\mathrm{s}}=10^{-15} \mathrm{~mol}\right)$. To confirm our results, we calculate the amount of $\mathrm{Li}_{3} \mathrm{VO}_{4}$ dissolved in a droplets as follows. Nanosized particles of $\mathrm{Li}_{3} \mathrm{VO}_{4}$ were assumed to be spherical shape with an approximate radius of $25 \mathrm{~nm}$ and mass density of $2.47 \times 10^{3}$ $\mathrm{g} \cdot \mathrm{m}^{-3}$. It is easy to derive the solute concentration as $1.18 \times 10^{-18}$ moles which is consistent with the initial value. The calculated value is in agreement with a previous report on the droplet size distribution of the water vapor system. ${ }^{32,33,34,35}$ As the vapor droplets act as sub-micro reactors, the primary particles are limited not only to growth but also condense together to form the final morphology, as shown in the FE-SEM image.

Additionally, the linear fitted Brunauer-Emmett-Teller (BET) results, (Figure S6), present the specific surface areas of all the samples, as summarized in Table 3. In detail, the two samples prepared by ABR possess a higher surface area than the corresponding SSR samples, with 3LCVO-ABR exhibiting the maximum surface area of $4.484 \mathrm{~m}^{2} \cdot \mathrm{g}^{-1}$ (3.2 and 29.5 times higher than those of 0LCVO-ABR and 0LCVO-SSR, respectively). The $t$-plot in Figure S7 indicates that ABR synthesis and Ca-doping tend to increase the $\mu$-pore area, while the pore size distribution in Figure S8 implies that the pore size was higher in 3LCVO-ABR when compared to the pure sample. These results demonstrate that the combination of $\mathrm{ABR}$ and $\mathrm{Ca}$-doping induces a mesoporous morphology and significantly increases the specific surface area. This in turn yields a strong interface between the active materials and electrolyte, leading to a higher reaction area and shortening of the $\mathrm{Li}^{+}$ion movement pathway. ${ }^{16,36,37}$ Such increase in the surface area can be explained as follows. When doping $\mathrm{Ca}$, the foreign atoms act as a modifying agent, which changes 
not only the surface energy but also the mobility and reaction kinetics as they exhibit different hydration energy and diffusivity when compared to $\mathrm{Li}^{+}$ions. Firstly, due to the more negative hydration enthalpy of $\mathrm{Ca}^{2+}\left(-1577 \mathrm{~kJ} \mathrm{~mol}^{-1}\right)$ as compared to $\mathrm{Li}^{+}\left(-520 \mathrm{~kJ} \mathrm{~mol}^{-1}\right)$, the absorbed $\mathrm{Ca}^{2+}$ could lower the reaction surface energy by enhancing the lattice surface tension of $\mathrm{Li}_{3} \mathrm{VO}_{4}{ }^{38} \mathrm{This}^{3}$ energy also reflects the fact that the stronger binding of $\mathrm{Ca}$ sites with water molecules inhibits further crystallization. Secondly, as water droplets act as sub-micro reactors, the main parameter determining the reaction rate is reactant diffusivity. As shown in (Equation 1, and 2), the reaction rate generally depends not only on the intrinsic reaction rate but also on the rate at which molecules diffuse close, to each other; this effect is called the diffusion-influenced reaction:

$$
\begin{aligned}
& \mathrm{A}+\mathrm{B} \underset{\mathrm{k}_{-\mathrm{d}}}{\stackrel{\mathrm{k}_{\mathrm{d}}}{\longrightarrow}}\{\mathrm{AB}\} \stackrel{\mathrm{k}_{\mathrm{r}}}{\longrightarrow} \operatorname{product}(\mathrm{s}) \\
& \frac{\mathrm{d}[\text { product }]}{\mathrm{dt}}=\mathrm{k}_{\mathrm{r}} \frac{\mathrm{k}_{\mathrm{d}}}{\mathrm{k}_{-\mathrm{d}}+\mathrm{k}_{\mathrm{r}}}[\mathrm{A}][\mathrm{B}]=\mathrm{k}[\mathrm{A}][\mathrm{B}]
\end{aligned}
$$

where, $\mathrm{kd}_{\mathrm{d}}$ and $\mathrm{k}-\mathrm{d}$ are reversible diffusion coefficients and $\mathrm{k}_{\mathrm{r}}$ is the intrinsic reaction rate. According to Equation 3, the diffusivity of $\mathrm{Ca}^{2+}$ ions $\left(7.93 \times 10^{-10} \mathrm{~m}^{2} \cdot \mathrm{s}^{-1}\right)$ is lower than that $\mathrm{of}^{+}$ions $\left(10.3 \times 10^{-10} \mathrm{~m}^{2} \cdot \mathrm{s}^{-1}\right)$ due to its larger size and higher valence. ${ }^{39}$ Therefore, the reaction at the Ca site could be slower than further crystal growth at a $\mathrm{Li}$ site. For the two reasons mentioned above, $\mathrm{Ca}^{2+}$ ions in $\mathrm{Li}_{3} \mathrm{VO}_{4}$ act as inhibitors, leading to a non-uniform surface with high porosity. This enhanced porosity is indicated by the significantly higher surface area of 3LCVO-ABR as compared to the remaining samples. To further confirm the effect of $\mathrm{Ca}^{2+}$ ions on surface area modification, $\mathrm{Ca}$ was replaced by magnesium $\left(\mathrm{Mg}^{2+}\right)$ (at the same content), which has a higher hydration enthalpy $\left(-1926 \mathrm{~kJ} \cdot \mathrm{mol}^{-1}\right)$ and lower diffusivity $\left(7.06 \times 10^{-10} \mathrm{~m}^{2} \cdot \mathrm{s}^{-1}\right)$. The XRD pattern of the Mg-doped sample in Figure S9 can be used to determine the purity of the prepared sample while the increase in BET surface area, large $\mu$-pore area, and large pore size of 3LMVO-ABR 
confirm the inhibitory effect of the dopant ions on particles growth, as demonstrated in Figure S68.

Subsequently, the chemical valence state of the elements present in the as-prepared samples were analyzed by X-ray photoelectron spectroscopy (XPS), as shown in Figure S10a. The V2p spectra of 0LCVO-ABR, 3LCVO-ABR and 3LCVO-SSR included $\mathrm{V}^{5+} 2 \mathrm{p}_{3 / 2}$ and $\mathrm{V}^{5+} 2 \mathrm{p}_{1 / 2}$ at binding energies of $\sim 517.0$ and $525.5 \mathrm{eV}$, respectively. In particular, the $\mathrm{V} 2 \mathrm{p}_{3 / 2}$ peak could be deconvoluted into two peaks; for example, in 3LCVO-ABR, the V2p $3 / 2$ peak could be deconvoluted into peaks at 517.74 and $516.27 \mathrm{eV}$ corresponding to $\mathrm{V}^{5+}$ and $\mathrm{V}^{4+}$, respectively. The estimated ratio of $\mathrm{V}^{4+} / \mathrm{V}^{5+}$ in the doped samples was $13.52 \%$ which is 6.66 times higher than that of pure material $(2.03 \%)$. In addition, the co-existence of pentavalent and tetravalent vanadium species could be explained by the compensation the unbalanced charges caused by the substitution of $\mathrm{Li}^{+}$with ions of higher valence according to the Knöger - Vink equation:

$$
\begin{aligned}
& 2 \mathrm{Li}_{\mathrm{Li}}^{\times} \rightarrow \mathrm{Li}_{\mathrm{Ca}}^{\bullet}+\mathrm{V}_{\mathrm{Li}}^{\prime} \\
& \text { or } \mathrm{Li}_{\mathrm{Li}}^{\times} \rightarrow \mathrm{Li}_{\mathrm{Ca}}^{\cdot}+\mathrm{e}^{\prime}
\end{aligned}
$$

in which excess electrons result in the reduction of $\mathrm{V}^{5+}$ to $\mathrm{V}^{4+}$ due to the oxygen corner-sharing location of $\mathrm{LiO}_{4}$ and $\mathrm{VO}_{4}$ tetrahedrons.

$$
\mathrm{V}^{5+}+\mathrm{e}^{\prime} \rightarrow \mathrm{V}^{4+}
$$

The additional formation of low-valence V-species, causes further enlargement in the lattice crystal due to the larger ionic radius of $\mathrm{V}^{4+}$ compared to $\mathrm{V}^{5+} \cdot{ }^{14,41,37}$ Furthermore, due to the increase in the content of low-valence species, Vo related to $\mathrm{V}^{4+}$ is reinforced, which leads to the disappearance of corner-sharing between $\mathrm{LiO}_{4}$ and $\mathrm{VO}_{4}$ tetrahedrons which lead to more space for $\mathrm{Li}^{+}$ions to diffuse. ${ }^{41}$ As shown in Figure $\mathrm{S} 10 \mathrm{~b}$, the O1s spectra of as-prepared samples could be distinguished into three components (for 3LCVO-ABR) such as the highest intensity peak at 
$530.26 \mathrm{eV}$ corresponding to oxygen bonding with lithium and vanadium in corner-sharing tetrahedrons and two weak constituents at 531.93 and $533.15 \mathrm{eV}$ related to oxygen defect and absorbed oxygen on the surface, respectively. ${ }^{10,25,42,43}$ From the Figure S10b, it can be calculated that the concentration of $\mathrm{V}_{\mathrm{O}}$ in $3 \mathrm{LCVO}-\mathrm{ABR}$ increased to $30.4 \%$ when compared to $6.8 \%$ in the pristine sample, which is proportional to the $\mathrm{V}^{4+}$ contents. Meanwhile, 3LCVO-SSR exhibited a oxygen defect content as $9.94 \%$ which indicates that a protective layer created by water vapor at low temperatures are advantageous for $\mathrm{V}_{\mathrm{O}}$ formation. Conversely, by treating at high temperatures in air, Vo can be partly filled and suppressed by excess ambient oxygen molecules thus reducing the Vo concentration to one-third of the value in doped ABR samples. The presence of lattice defects and the single electron configuration of $3 \mathrm{~d}^{1}$ in $\mathrm{V}^{4+}$ was confirmed by electron spin resonance (ESR, Figure S11).

To confirm the formation of oxygen vacancies and increase in $\mathrm{V}^{4+}$ species induced by Ca doping, DFT calculations were conducted. It was found that the Ca dopants reduced the formation energy of oxygen vacancy, $E_{\mathrm{vac}}$, in $\mathrm{Li}_{3} \mathrm{VO}_{4}$ (Table S5). The average $E_{\mathrm{vac}}$ of three types of oxygen ions $(\mathrm{O} 1, \mathrm{O} 2$, and $\mathrm{O} 3)$ in $\mathrm{Li}_{3} \mathrm{VO}_{4}(3.99 \mathrm{eV})$ was slightly decreased to $3.50 \mathrm{eV}$ upon $\mathrm{Ca}$ doping. However, the $E_{\mathrm{vac}}$ of specific oxygen species (O1, highlighted in blue in Figure S3c), which was composed of a tetrahedron with the $\mathrm{V}$ ion at the central site between two Ca dopants (highlighted in yellow in Figure S3d), decreased from 4.06 to $3.33 \mathrm{eV}$. This finding indicates that the effect of $\mathrm{Ca}$ doping is highly localized and that extra oxygen defects can be formed around the dopants. Bader charge analysis shows that the $\mathrm{V}^{5+}$ ion located between two $\mathrm{Ca}$ dopants was reduced upon Ca doping (Figure 3e). The electron density difference map estimated by abstracting the electron density of $\mathrm{Li}_{48} \mathrm{~V}_{16} \mathrm{O}_{64}$ from that of $\mathrm{Li}_{46} \mathrm{Ca}_{2} \mathrm{~V}_{16} \mathrm{O}_{64}$ shows that the extra electrons donated by $\mathrm{Ca}$ dopants are localized to $\mathrm{V}$ and adjacent $\mathrm{O}^{2-}$ ions (Figure $3 \mathrm{f}$ ). These results 
corroborate the dual-functionality of Ca dopants, viz. 1) directly donating electrons to $\mathrm{V}^{5+}$ ions, and 2) accelerating the generation of oxygen vacancies which can further reduce $\mathrm{V}^{5+}$ ions. Therefore, the effects of $\mathrm{Li}^{+}$substitution with higher valence ions, co-existence of $\mathrm{V}^{4+}$ and $\mathrm{V}^{5+}$ and $V_{0}$ formation are all related to the increase in excess free electron defects in the structure. This enhances the electronic conductivity of the material and reduces the polarization during the insertion and extraction of $\mathrm{Li}^{+}$ions into or from $\mathrm{Li}_{3} \mathrm{VO}_{4}$ lattice, which positively impacts materials' cyclability and rate performances..$^{40,44,45}$

The galvanostatic charge-discharge results of all the tested samples corresponding to the first cycle are presented in Figure 4a. A typical discharge profile includes a sharp slope at voltages higher than $0.8 \mathrm{~V}$ attributed to lithium ion insertion into the lattice and a smooth region with two characteristic plateaus at $\sim 0.75$ and $0.6 \mathrm{~V}$ indicative of the interaction between active materials and the electrolyte, leading to the formation of a solid electrolyte interphase (SEI) layer in the first few cycles. ${ }^{21,46}$ Although all samples exhibited similar curves, the initial discharge capacity and first coulombic efficiency (CE) of the doped and ABR-samples showed obvious enhancement. The initial charge/discharge capacities of pure SSR and ABR samples were quite similar at 263.43/441.79 and 305.4/568.91 mAh.g ${ }^{-1}$ with a CE of 59.63 and 53.68\%, respectively. However, the first discharge capacity of $3 \mathrm{LCVO}-\mathrm{ABR}$ was as high as $946.78 \mathrm{mAh} \cdot \mathrm{g}^{-1}$ with a very high CE of $74.19 \%$. The huge loss of capacity in the few first cycles could be ascribed to irreversible lithium ion loss due to side reactions, including formation of SEI layer and electrolyte decomposition. ${ }^{47,48}$ The apparent increase in the capacity of doped ABR sample could be explained by the effect of particle size and specific surface area. ${ }^{49}$ The nanosized particles and higher surface area in ABR samples are favorable for improving electron exchange and reaction surface contact, which contribute to their high capacity. In the case of 3LCVO-ABR, its high surface area might 
explain for its highest capacity, while the enhanced $\mathrm{CE}$ value might be associated with the increase in electronic conductivity due to Ca doping. ${ }^{40,44,45} \mathrm{The}$ substitution of $\mathrm{Li}^{+}$with higher valence ions not only generates excess electrons but also change the electronic band structure, leading to the shift of Fermi level toward the conduction band (due to the reduction of $\mathrm{V}^{5+}$ ). ${ }^{44,45}$ Furthermore, another important reason related to the low first $\mathrm{CE}$ of $\mathrm{Li}_{3} \mathrm{VO}_{4}$ could be ascribed to crystallite distortion due to the large amount of Li ions inserted or extracted during the first charge/discharge process. ${ }^{46}$ The higher the number of $\mathrm{Li}$ ions inserted to form $\mathrm{Li}_{3+x} \mathrm{VO}_{4}$ (especially $x>2$ ), the more monoclinic (even triclinic, at $x=3$ ) is the distortion from the original orthorhombic phase. The higher $\mathrm{CE}$ of $3 \mathrm{LCVO}$ samples compared to the pure samples demonstrates the positive effect of Ca doping in enhancing the structural flexibility under deeply lithium exchange.

In addition, it can be observed that at a current density of $100 \mathrm{~mA} \cdot \mathrm{g}^{-1}$, the cycling performance of the doped samples prepared by ABR was enhance. The fading capacity of all sample in the few first cycles could be regarded as the initial activation required to lower the insertion barrier by irreversible phase transition. ${ }^{46}$ However, the ABR samples exhibited the superior capacity retention of $92.72 \%, 94.27 \%$ and $89.72 \%$ after 200 cycles for $x$ LCVO-ABR $(x$ $=1,3,5$, respectively) and $90.27 \%$ for $0 \mathrm{LCVO}-\mathrm{ABR}$. The decrease in capacity retention beyond doping concentration of $3 \%$ can be explained by the lithium ion diffusion blocking effect at high level of doping. However, the 0LCVO-SSR and 3LCVO-SSR samples could retain only $55.76 \%$ and $76.09 \%$ after 200 cycles for 0LCVO-SSR and 3LCVO-SSR, respectively. This means that the ABR samples not only showed greater cycling performance but also delivered higher reversible capacity, $543.1 \mathrm{mAh} \cdot \mathrm{g}^{-1}$ (for 3LCVO-ABR) and $268.7 \mathrm{mAh} \cdot \mathrm{g}^{-1}$ (for 0LCVO-ABR) after 200 cycles. Even at a higher current density of $400 \mathrm{~mA} \cdot \mathrm{g}^{-1}$ (Figure 4c), 3LCVO-ABR still displayed the highest reversible capacity and capacity retention. Meanwhile, the SSR samples revealed poor 
cyclability with a dramatic crash in capacity after only a few cycles. The high reversible capacity 3LCVO-ABR could be ascribed to the contribution of pseudocapacitive lithium ion storage pathway, which will be demonstrated in the following discussion.

Beside the excellent cycling performance, the rated performance at current densities in the range of 50 to $800 \mathrm{~mA} \cdot \mathrm{g}^{-1}$ of Ca-doped ABR samples ( Figure 4c) was improved. At a current density of $50 \mathrm{~mA} \cdot \mathrm{g}^{-1}$, the capacity of $3 \mathrm{LCVO}-\mathrm{ABR}$, was higher than $600 \mathrm{mAh} \cdot \mathrm{g}^{-1}$, which is greater than theoretical specific capacity of $\mathrm{Li}_{3} \mathrm{VO}_{4}\left(591 \mathrm{mAh} \cdot \mathrm{g}^{-1}\right)$, attributed to the continuous formation of a jelly-like polymeric SEI layer due to the unstable nature of this layer to electrolyte. ${ }^{46,50,51}$ In addition, at low potential, the interfacial storage mechanism ${ }^{52,53,54}$ may also explain the extra capacity. ${ }^{55,56,57}$ The excellent cycling behavior and rated performance of the ABR samples, especially 3LCVO-ABR, may be attributed to their enhanced electronic conductivity and $\mathrm{Li}^{+}$ion diffusivity, as demonstrated by the EIS data in Figure $4 \mathrm{~d}$ and $\mathrm{S} 13$. All the obtained EIS curves included a semicircle at high frequencies corresponding to charge-transfer resistance and a linear incline in the low-frequency region corresponding to the $\mathrm{Li}^{+}$ion diffusivity in the electrodes. The results of EIS fitting, deduced using the equivalent circuit model as shown in Figure S12, are summarized in Table 4. It can be noted that the doped samples exhibited a lower charge transfer resistance, which is consistent with our previous observation. Furthermore, the diffusion coefficient of lithium ions was calculated using the EIS data in the inclined region following the method presented in SI part (Figure S13). The lowest $\mathrm{Li}^{+}$ion diffusion coefficient obtained for 3LCVO-ABR indicates that the mobility of Li-ions was effectively accelerated by the expanding the lattice parameter and increasing the surface area of the electrode.

To investigate the practical application potential of the synthesized 3LCVO-ABR as

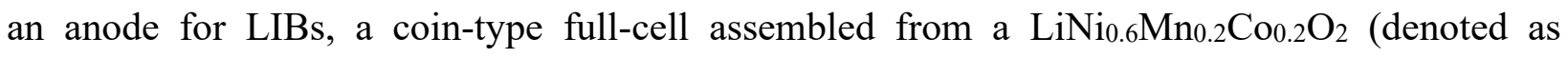


NMC622) cathode and 3LCVO-ABR anode was prepared. To eliminate rapid capacity fading caused by irreversible lithium consumption in the first few cycles, the 3LCVO-ABR electrode was pre-lithiated for 20 cycles in another half-cell at a current density of $50 \mathrm{~mA} \cdot \mathrm{g}^{-1}$ before full-cell assembly. ${ }^{58,59}$ Another full-cell comprising of a commercial graphite (CG) anode and NMC622 cathode was also assembled for comparison. Figure 4e shows the galvanostatic profile of the NMC622 || 3LCVO-ABR full-cell at a current density of $50 \mathrm{~mA} \cdot \mathrm{g}^{-1}$. In the first cycle, the NMC622\|3LCVO-ABR full cell delivered the specific discharge capacity of $462.8 \mathrm{~mA} \cdot \mathrm{g}^{-1}$. After 50 cycles, the full cell of the 3LCVO-ABR anode still offered a specific discharge capacity of $429.1 \mathrm{mAh} \cdot \mathrm{g}^{-1}$ with a capacity retention of $92.7 \%$. At the same conditions of discharge and charge, the full cell of the CG anode, however, only delivered the first specific discharge capacity of 350.6 $\mathrm{mA} \cdot \mathrm{g}^{-1}$ with a capacity retention of $60.0 \%$ after 50 cycles, corresponding to capacity loss of $0.79 \%$ per a cycle. The capacity and cyclability behaviors of the full cells also can be enhanced further if the cycling conditions is optimized. ${ }^{59,60}$ The obtained results of the full cells could be a proof for the perspective of the $3 \mathrm{LCVO}-\mathrm{ABR}$ as promising practical candidate for LIBs anode.

Figure 5a shows the cyclic voltammetry $\mathrm{CV}$ results of 3LCVO-ABR for four initial cycles while the $\mathrm{CV}$ curves in the second cycle corresponding to pure and representative doped samples synthesized by ABR are shown in Figure S14b. Pristine ABR-Li3VO4 showed the $2^{\text {nd }}$ cathodic peaks at 0.500 and $0.846 \mathrm{~V}$, corresponding to the reduction of $\mathrm{V}^{5+}$ to $\mathrm{V}^{4+}$ and $\mathrm{V}^{3+}$ species, respectively, and an anodic peak at $\sim 1.168 \mathrm{~V}$ related to the reversible oxidation of $\mathrm{V}^{3+} .{ }^{15}$ Meanwhile, the $3 \mathrm{LCVO}-\mathrm{ABR}$ displayed three peaks at $0.60,0.896$ and $1.108 \mathrm{~V}$. This means that based on the doping strategy, peaks corresponding to reduction tend to shift to higher voltage regions while the oxidation peak moves toward lower potentials which reduces the voltage gaps from $0.668 / 0.322 \mathrm{~V}$ for pristine samples to $0.504 / 0.212 \mathrm{~V}$ in $3 \mathrm{LCVO}-\mathrm{ABR}$. The observed potential 
values corresponding to reduction and oxidation peaks are summarized in Table 5. The smaller voltage gap reconfirms our observation on reducing polarization in the electrode and accelerating lithium diffusion, ${ }^{13,61}$ which is beneficial for cycling and rate performance.

As previously noted, the higher specific capacity of $3 \mathrm{LCVO}-\mathrm{ABR}$ compared to pristine samples and the theoretical value can be explained by the existence of additional lithium ion storage sites following the capacitive performance of the lithium ions adsorbed on the appropriate surface of the electrode material..$^{62,63,64,65,66}$ The most important requirement for the EDLC behavior is an ultrahigh specific surface area (up to $2000 \mathrm{~m}^{2} \cdot \mathrm{g}^{-1}$ ), ${ }^{63,67}$ which was not adapted in the case of 3LCVO-ABR. This assumes that, besides the contribution of the diffusion-controlled process, the total charge storage of $3 \mathrm{LCVO}-\mathrm{ABR}$ electrode is only assigned to the pseudocapacitance.

To estimate the contribution of each portion to the total charge storage of the 3LCVOABR electrode, a series of $\mathrm{CV}$ plots were plotted at scan rates of $0.1-5.0 \mathrm{mV} \cdot \mathrm{s}^{-1}$ in the potential range of $0.2-3.0 \mathrm{~V}$, vs. $\mathrm{Li} / \mathrm{Li}^{+}$(Figure $5 \mathrm{~b}$ ). The detailed calculation is described in the $\mathrm{SI}$. As shown in Figure $5 \mathrm{c}$, the obtained $b$-values fluctuate with minimums of 0.588 at $\sim 1.2 \mathrm{~V}$ (cathodic) or 0.66 at $\sim 0.82 \mathrm{~V}$ and $\sim 0.57$ at range below $0.5 \mathrm{~V}$ (anodic), which is consistent with the main reduction or oxidation peaks. This illustrates that closer to the main redox peaks, the contribution of faradaic process controlled by the solid phase diffusion becomes predominant. If the selected points are far away from the main redox peaks, the characteristic of the pseudocapacitive effect (equation S8) become main contribution. The pictorial estimation represented in Figure 5e, defined that pseudocapacitance accounts for $34.4 \%$ of the total capacity at scan rate of $0.1 \mathrm{mV} \cdot \mathrm{s}^{-1}$.

Based on a similar procedure, we conducted ABR synthesis of various compounds and applied them as active materials for LIBs and SIBs. A brief summary on the electrochemical 
performance of these ABR compound is included in Table S6; these value strongly confirm the prospective application of ABR strategy for the synthesis of active materials for low-cost and sustainable energy storage device in the near future.

\section{Conclusion}

In this study, for the first time, a green and environmentally friendly pathway of humidity-assisted ABR was employed to synthesize a variety of active materials for LIBs and SIBs. A combination of ABR and Ca-doping strategies, which significantly enhanced the electrochemical performance of $\mathrm{Li}_{3} \mathrm{VO}_{4}$ anodes for LIBs, has been investigated to understand the reaction mechanism corresponding to $\mathrm{ABR}$ synthesis. The proposed mechanism, which illustrates the role of sub-micro reactors of vapor droplets, details the effect of nanosized particles, while doping increased crystal lattice parameters, led to the formation of beneficial defects, and induced surface modification to increase the specific surface area. The high reversible capacity and longlife cycling behavior are attributed to the synergic effects of modification in lattice structure, the favorable morphology which could not only accelerate the diffusivity of charge carriers but also offer the extra contribution to final energy storage via a pseudocapacitance strategy.

Acknowledgement. This research was supported by the Basic Science Research Program through the National Research Foundation of Korea (NRF), funded by the Ministry of Science, ICT and Future Planning (NRF-2017R1A2B3011967). This work was supported by the Engineering Research Center through the NRF, funded by the Korean Government (MSIT), (NRF2018R1A5A1025224).

\section{Author Contribution}


H.T.H. conceptualization, synthesizing materials, conducting physico- and electrochemical analysis, writing manuscript; N.H.V. conducting electrochemical analysis; H.W.H. and H.Y.K. conducting DFT calculation; J.H.M. conducting in situ Raman spectroscopy; W.B.I. conceptualization, correcting manuscript and administering projects.

\section{Competing interest}

No competing interest is declared.

\section{References}

1. Hwang JY, Myung ST, Sun YK. Sodium-ion batteries: present and future. Chemical Society reviews 46, 3529-3614 (2017).

2. Yan G, et al. Higher energy and safer sodium ion batteries via an electrochemically made disordered $\mathrm{Na}_{3} \mathrm{~V}_{2}\left(\mathrm{PO}_{4}\right)_{2} \mathrm{~F}_{3}$ material. Nature communications 10, 1-12 (2019).

3. Yoo HD, Shterenberg I, Gofer Y, Gershinsky G, Pour N, Aurbach D. Mg rechargeable batteries: an on-going challenge. Energy \& Environmental Science 6, 2265 (2013).

4. Li Z, et al. Fast kinetics of multivalent intercalation chemistry enabled by solvated magnesium-ions into self-established metallic layered materials. Nature communications 9, 1-13 (2018).

5. Wang D-Y, et al. Advanced rechargeable aluminium ion battery with a high-quality natural graphite cathode. Nature communications 8, 1-7 (2017).

6. Nitta N, Wu F, Lee JT, Yushin G. Li-ion battery materials: present and future. Materials Today 18, 252-264 (2015).

7. Shibuta Y, Hasegawa T, Kim S-W, Uematsu K, Toda K, Sato M. Mild condition synthesis without high temperature process of $\mathrm{Eu}^{2+}$-doped barium orthosilicate nanophosphor via 
Water-Assisted Solid-State Reaction (WASSR) method. Journal of Alloys and Compounds 788, 1009-1012 (2019).

8. Kim SW, et al. Nanophosphors synthesized by the water-assisted solid-state reaction (WASSR) method: Luminescence properties and reaction mechanism of the WASSR method. Applied Spectroscopy Reviews 53, 177-194 (2017).

9. Watanabe $\mathrm{M}$, et al. Synthesis of $\mathrm{Li}_{2} \mathrm{SiO}_{3}$ using novel water-assisted solid state reaction method. Journal of the Ceramic Society of Japan 125, $472-475$ (2017).

10. Ni S, et al. Approaching the Theoretical Capacity of $\mathrm{Li}_{3} \mathrm{VO}_{4}$ via Electrochemical Reconstruction. Advanced Materials Interfaces 3, 1500340 (2016).

11. Li H, Liu X, Zhai T, Li D, Zhou H. $\mathrm{Li}_{3} \mathrm{VO}_{4}$ : A Promising Insertion Anode Material for Lithium-Ion Batteries. Advanced Energy Materials 3, 428-432 (2013).

12. Arroyo-de Dompablo ME, Tartaj P, Amarilla JM, Amador U. Computational investigation of $\mathrm{Li}$ insertion in $\mathrm{Li}_{3} \mathrm{VO}_{4}$. Chemistry of Materials 28, 5643-5651 (2016).

13. Dong Y, Duan H, Park K-s, Zhao Y. $\mathrm{Mo}^{6+}$ doping in $\mathrm{Li}_{3} \mathrm{VO}_{4}$ anode for $\mathrm{Li}$-ion batteries: significantly improve the reversible capacity and rate performance. ACS Applied Materials \& Interfaces 9, 27688-27696 (2017).

14. Wang $\mathrm{K}$, et al. Enhancing the Rate Performance of a $\mathrm{Li}_{3} \mathrm{VO}_{4}$ Anode through $\mathrm{Cu}$ Doping. ChemElectroChem 5, 478-482 (2018).

15. Mu C, Lei K, Li H, Li F, Chen J. Enhanced Conductivity and Structure Stability of Ti4+ Doped $\mathrm{Li}_{3} \mathrm{VO}_{4}$ as Anodes for Lithium-Ion Batteries. The Journal of Physical Chemistry C 121, 26196-26201 (2017).

16. Zhang $\mathrm{C}$, et al. Effects of high surface energy on lithium-ion intercalation properties of $\mathrm{Ni}$ doped Li3VO4. NPG Asia Materials 8, e287-e287 (2016). 
17. Liu J, et al. Ultrathin $\mathrm{Li}_{3} \mathrm{VO}_{4}$ nanoribbon/graphene sandwich-like nanostructures with ultrahigh lithium ion storage properties. Nano Energy 12, 709-724 (2015).

18. Shi $\mathrm{Y}$, et al. Hollow structured $\mathrm{Li}_{3} \mathrm{VO}_{4}$ wrapped with graphene nanosheets in situ prepared by a one-pot template-free method as an anode for lithium-ion batteries. Nano Lett 13, 4715-4720 (2013).

19. Zelang Jian, et al. $\mathrm{Li}_{3} \mathrm{VO}_{4}$ anchored graphene nanosheets for long-life and high-rate lithium-ion batteries. Chem Commun 51, 229 (2015).

20. Li Q, et al. A unique hollow $\mathrm{Li}_{3} \mathrm{VO}_{4} /$ carbon nanotube composite anode for high rate longlife lithium-ion batteries. Nanoscale 6, 11072 (2014).

21. Jicheng Z, Shibing N, Tao K, Jun T, Xuelin Y, Lulu Z. Prominent electrochemical performance of a $\mathrm{Li}_{3} \mathrm{VO}_{4} / \mathrm{C}-\mathrm{Ni}$ anode via hierarchically porous architecture design. Journal of Materials Chemitry A 4, 14101 (2016).

22. Li Q, et al. Mesoporous $\mathrm{Li}_{3} \mathrm{VO}_{4} / \mathrm{C}$ Submicron-Ellipsoids Supported on Reduced Graphene Oxide as Practical Anode for High-Power Lithium-Ion Batteries. Advanced Science (Weinh) 2, 1500284 (2015).

23. Shen L, Chen S, Maier J, Yu Y. Carbon-Coated $\mathrm{Li}_{3} \mathrm{VO}_{4}$ Spheres as Constituents of an Advanced Anode Material for High-Rate Long-Life Lithium-Ion Batteries. Advanced Materials 29, 1701571 (2017).

24. Wang $\mathrm{X}$, et al. Facile Synthesis of Carbon-Coated $\mathrm{Li}_{3} \mathrm{VO}_{4}$ Anode Material and its Application in Full Cells. Energy Technology 6, 2074-2081 (2018).

25. Zhou J, et al. The enhanced cycling stability and rate capability of sodium-modified Li3VO4 anode material for lithium-ion batteries. Solid State Ionics 322, 30-38 (2018). 


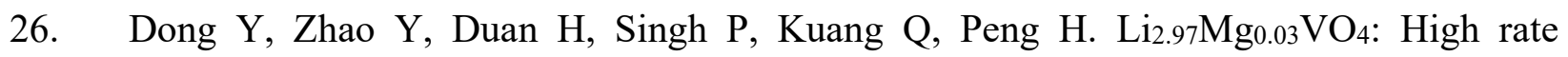
capability and cyclability performances anode material for rechargeable Li-ion batteries. Journal of Power Sources 319, 104-110 (2016).

27. Bose R, Manna G, Pradhan N. Surface Doping for Hindrance of Crystal Growth and Structural Transformation in Semiconductor Nanocrystals. The Journal of Physical Chemistry C 117, 20991-20997 (2013).

28. Mondal O, Pal M, Singh R, Sen D, Mazumder S, Pal M. Influence of doping on crystal growth, structure and optical properties of nanocrystalline $\mathrm{CaTiO}_{3}$ : a case study using small-angle neutron scattering. Journal of Applied Crystallography 48, 836-843 (2015).

29. Gorelik VS, et al. Raman spectra of lithium compounds. Journal of Physics: Conference Series 918, 012035 (2017).

30. C.L. Londono-Calder, C. Vargas-Hernandez, Jurado JF. Desorption influence of water on structural, electrical properties and molecular order of vanadium pentoxide xerogel films. REVISTA MEXICANA DE FISICA 56 411-415 (2010).

31. Qin R, Shao G, Hou J, Zheng Z, Zhai T, Li H. One-pot synthesis of $\mathrm{Li}_{3} \mathrm{VO}_{4} @ \mathrm{C}$ nanofibers by electrospinning with enhanced electrochemical performance for lithium-ion batteries. Science Bulletin 62, 1081-1088 (2017).

32. Song T, Lan Z, Ma X, Bai T. Molecular clustering physical model of steam condensation and the experimental study on the initial droplet size distribution. International journal of thermal sciences 48, 2228-2236 (2009).

33. Wróblewski W, Dykas S. Two-fluid model with droplet size distribution for condensing steam flows. Energy 106, 112-120 (2016). 
34. Mirhoseini MS, Boroomand M. Control of wetness fraction and liquid droplet size in wet steam two phase flows with hot steam injection. Meccanica 53, 193-207 (2018).

35. Tatsuno K, Nagao S. Water droplet size measurements in an experimental steam turbine using an optical fiber droplet sizer. Journal of Heat Transfer 108(4), 939-945 (1986).

36. Yi T-F, Shu J, Zhu Y-R, Zhu X-D, Zhu R-S, Zhou A-N. Advanced electrochemical performance of $\mathrm{Li}_{4} \mathrm{Ti}_{4} 4.95 \mathrm{~V}_{0.05} \mathrm{O}_{12}$ as a reversible anode material down to $0 \mathrm{~V}$. Journal of Power Sources 195, 285-288 (2010).

37. Zhou J, et al. Optimization of Rate Capability and Cyclability Performance in $\mathrm{Li}_{3} \mathrm{VO}_{4}$ Anode Material through Ca Doping. Chemistry A European Journal 23, 16338-16345 (2017).

38. Yuan Y, Zhan W, Yi H, Zhao Y, Song S. Molecular dynamics simulations study for the effect of cations hydration on the surface tension of the electrolyte solutions. Colloids and Surfaces A: Physicochemical and Engineering Aspects 539, 80-84 (2018).

39. Jacques B, Zeshi Z, Konstantin S. Metal Flux and Dynamic Speciation at (Bio)interfaces. Part I: Critical Evaluation and Compilation of Physicochemical Parameters for Complexes with Simple Ligands and Fulvic/Humic Substances. Environmental Science \& Technology 41, 7609-7620 (2007).

40. Qiu C, Yuan Z, Liu L, Cheng S, Liu J. Sol-gel Synthesis and Electrochemical Performance of $\mathrm{Li}_{4-\mathrm{x}} \mathrm{Mg}_{\mathrm{x}} \mathrm{Ti}_{5-\mathrm{x}} \mathrm{Zr}_{\mathrm{x}} \mathrm{O}_{12}$ Anode Material for Lithium-ion Batteries. Chinese Journal of Chemistry 31, 819-825 (2013).

41. Chen L, Jiang X, Wang N, Yue J, Qian Y, Yang J. Surface-Amorphous and OxygenDeficient $\mathrm{Li}_{3} \mathrm{VO}_{4-\delta} \delta$ as a Promising Anode Material for Lithium-Ion Batteries. Advanced Science (Weinh) 2, 1500090 (2015). 
42. Sara R, Jing HH, Wei C, Kai W, Guo QX. Tuning the electronic and structural properties of WO3 nanocrystals by varying transition metal tungstate precursors. RSC Advances $\mathbf{4}$, 62423 (2014).

43. Linghua $\mathrm{J}$, et al. $\mathrm{BiFeO}_{3}(001) / \mathrm{LaNiO}_{3} / \mathrm{Si}$ thin films with enhanced polarization: an allsolution approach. RSC Advances 6, 78629 (2016).

44. Wang L, et al. Structural and Electrochemical Characteristics of Ca-Doped "Flower-like" $\mathrm{Li}_{4} \mathrm{Ti}_{5} \mathrm{O}_{12}$ Motifs as High-Rate Anode Materials for Lithium-Ion Batteries. Chemistry of Materials 30, 671-684 (2018).

45. Sen N, Chunsong L, Hongrui P, Guicun L, Kezheng C. Ti ${ }^{3+}$ self-doped $\mathrm{Li}_{4} \mathrm{Ti}_{5} \mathrm{O}_{12}$ nanosheets as anode materials for high performance lithium ion batteries. RSC $A d v \mathbf{5}$, $23278(2015)$.

46. Liao C, Wen Y, Shan B, Zhai T, Li H. Probing the capacity loss of $\mathrm{Li}_{3} \mathrm{VO}_{4}$ anode upon $\mathrm{Li}$ insertion and extraction. Journal of Power Sources 348, $48-56$ (2017).

47. Song JH, et al. Electrochemical characteristics of lithium vanadate, $\mathrm{Li}_{1+\mathrm{x}} \mathrm{VO}_{2}$, new anode materials for lithium ion batteries. Journal of Power Sources 195, 6157-6161 (2010).

48. Chunnian H, Shan W, Naiqin Z, Chunsheng S, Enzuo L, Jiajun L. Carbon-Encapsulated $\mathrm{Fe}_{3} \mathrm{O}_{4}$ Nanoparticles as a High-Rate Lithium Ion Battery Anode Material. ACS Nano 7, 4459 (2013).

49. Gaoqi S, Lin G, Ying M, Huiqiao L, Tianyou Z. Enhancing the performance of $\mathrm{Li}_{3} \mathrm{VO}_{4}$ by combining nanotechnology and surface carbon coating for lithium ion batteries. J Mater Chem A 3, 11253 (2015).

50. Grugeon S, Laruelle S, Dupont L, Tarascon JM. An update on the reactivity of nanoparticles Co-based compounds towards Li. Solid State Sciences 5, 895-904 (2003). 
51. Gachot G, et al. Deciphering the multi-step degradation mechanisms of carbonate-based electrolyte in Li batteries. Journal of Power Sources 178, 409-421 (2008).

52. Ponrouch A, Taberna P-L, Simon P, Palacin MR. On the origin of the extra capacity at low potential in materials for Li batteries reacting through conversion reaction. Electrochimica Acta 61, 13-18 (2012).

53. Balaya P, Bhattacharyya A, Jamnik J, Zhukovskii YF, Kotomin E, Maier J. Nano-ionics in the context of lithium batteries. Journal of Power Sources 159, 171-178 (2006).

54. Zhukovskii YF, Balaya P, Kotomin EA, Maier J. Evidence for interfacial-storage anomaly in nanocomposites for lithium batteries from first-principles simulations. Physical review letters 96, 058302 (2006).

55. Guan $\mathrm{H}$, et al. $\mathrm{CoO}$ octahedral nanocages for high-performance lithium ion batteries. Chemical Communications 48, 4878-4880 (2012).

56. Wang $\mathrm{X}$, et al. Mo-doped $\mathrm{SnO}_{2}$ mesoporous hollow structured spheres as anode materials for high-performance lithium ion batteries. Nanoscale 7, 3604-3613 (2015).

57. Wu R, et al. In-situ formation of hollow hybrids composed of cobalt sulfides embedded within porous carbon polyhedra/carbon nanotubes for high-performance lithium-ion batteries. Advanced Materials 27, 3038-3044 (2015).

58. Chae C, Noh H-J, Lee JK, Scrosati B, Sun Y-K. A High-Energy Li-Ion Battery Using a Silicon-Based Anode and a Nano-Structured Layered Composite Cathode. Advanced Functional Materials 24, 3036-3042 (2014).

59. Ngo DT, et al. Mass-scalable synthesis of 3D porous germanium-carbon composite particles as an ultra-high rate anode for lithium ion batteries. Energy \& Environmental Science 8, 3577-3588 (2015). 
60. Fang-Wei Yuan H-JY, and Hsing-Yu Tuan. Alkanethiol-Passivated Ge Nanowires as High-Performance Anode Materials for Lithium-Ion Batteries: The Role of Chemical Surface Functionalization. ACS Nano 6, 9932 —9942 (2012).

61. Zhanyu L, Jianling L, Yuguang Z, Kai Y, Fei G, Xiao L. Structure and electrochemical properties of Smdoped $\mathrm{Li}_{4} \mathrm{Ti}_{5} \mathrm{O}_{12}$ as anode material for lithium-ion batteries. RSC Advances 6, 15492 (2016).

62. Tran Huu H, Nguyen Thi XD, Nguyen Van K, Kim SJ, Vo V. A Facile Synthesis of $\mathrm{MoS}_{2} / \mathrm{g}-\mathrm{C}_{3} \mathrm{~N}_{4}$ Composite as an Anode Material with Improved Lithium Storage Capacity. Materials (Basel) 12, (2019).

63. Yu F, Liu Z, Zhou R, Tan D, Wang H, Wang F. Pseudocapacitance contribution in borondoped graphite sheets for anion storage enables high-performance sodium-ion capacitors. Materials Horizons 5, 529-535 (2018).

64. Cook JB, Kim H-S, Lin TC, Lai C-H, Dunn B, Tolbert SH. Pseudocapacitive Charge Storage in Thick Composite $\mathrm{MoS}_{2}$ Nanocrystal-Based Electrodes. Advanced Energy Materials 7, (2017).

65. Xiang Y, et al. Pseudocapacitive behavior of the Fe2O3 anode and its contribution to high reversible capacity in lithium ion batteries. Nanoscale 10, 18010-18018 (2018).

66. Chen $\mathrm{C}$, et al. $\mathrm{Na}^{+}$intercalation pseudocapacitance in graphene-coupled titanium oxide enabling ultra-fast sodium storage and long-term cycling. Nature communications $\mathbf{6}, 1-8$ (2015).

67. Seiichiro Tabata YI, and Masayoshi Watanabe. Inverse Opal Carbons Derived from a Polymer Precursor as Electrode Materials for Electric Double-Layer Capacitors. Journal of The Electrochemical Society 155, K42-K49 (2008). 



\section{Figures and Tables}

\section{Figure caption}

Figure 1. (a) XRD pattern of xLCVO-ABR and -SSR $(x=0,1,3,5)$ (inset: expansion of XRD pattern at $2 \theta=31-34^{\circ}$ ); Riveld refinement based on HR-XRD of (b) OLCVO-ABR and (c) 3LCVO-ABR; (d) Crystal structure of Ca-doped $\mathrm{Li}_{3} \mathrm{VO}_{4}$ at 3\% of dopant: lithium, vanadium and oxygen atoms were presented by purple, grey and red ball while Ca occupancy was presented by green contribution; dependence of lattice parameters $\left(\mathrm{e}_{1}\right) a,\left(\mathrm{e}_{2}\right) b,\left(\mathrm{e}_{3}\right) c$ and $\left(\mathrm{e}_{4}\right)$ unit cell volume on content of Ca-dopant.

Figure 2. SEM images of (a) 0LCVO-ABR and (b) 3LCVO-ABR; (c) TEM; (d) HR-TEM images and (e) SAED pattern of 3LCVO-ABR, the FFT image for square inset and the yellow line profile for rectangle inset; (f) the proposal mechanism of ABR process and the effect of Ca-doping on the morphology modification of 3LCVO-ABR.

Figure 3. Morphology of the $\mathrm{Li}_{46} \mathrm{Ca}_{2} \mathrm{~V}_{16} \mathrm{O}_{64}$ supercell via (a) (010), and (b) (001) plane direction; location of oxygen species used for $\mathrm{E}_{\mathrm{vac}}$ calculation: (c) $\mathrm{Li}_{48} \mathrm{~V}_{16} \mathrm{O}_{64}$ and (d) $\mathrm{Li}_{46} \mathrm{Ca}_{2} \mathrm{~V}_{16} \mathrm{O}_{64}$. Electron density analysis results. (e) The electron density difference map ( $\left.\rho=0.05 \mathrm{e} / \AA^{3}\right)$ estimated by abstracting the electron density of $\mathrm{Li}_{48} \mathrm{~V}_{16} \mathrm{O}_{64}$ from that of $\mathrm{Li}_{46} \mathrm{Ca}_{2} \mathrm{~V}_{16} \mathrm{O}_{64}$. The yellow highlighted

shades present at which extra electrons are localized. (f) The sliced single atomic layer of $\mathrm{Li}_{46} \mathrm{Ca}_{2} \mathrm{~V}_{16} \mathrm{O}_{64}$ involving the $\mathrm{Ca}$ dopants. The electron charge density map and the Bader charge analysis results are accordingly presented. The $\Delta \rho$ denotes the Bader charge difference. The ions with negative $\Delta \rho$ are enriched with extra electrons.

Figure 4. (a) the first galvanostatic charge-discharge curves (b) cycling performance and (c) c-rate behavior (d) EIS fitting analysis of $x$ LCVO-ABR and -SSR $(x=0,1,3,5)$; (e) galvanostatic 
charge-discharge curve and (f) cycling performance of full-cell of NMC622 cathode and 3LCVOABR anode or CG.

Figure 5. (a) $\mathrm{CV}$ of $3 \mathrm{LCVO}-\mathrm{ABR}$; (b) $\mathrm{CV}$ of $3 \mathrm{LCVO}-\mathrm{ABR}$ at various scan rate $\mathrm{n}=0.1-5.0$ $\mathrm{mV} \cdot \mathrm{s}^{-1}$; (c) dependence of $\mathrm{b}$-value on potential in range of cathodic (red color) and anodic (blue color) peaks; (d) linear fitting of $\log (\mathrm{i})$ vs. $\log (\mathrm{v})$ for determination of b-value; (e) pictorial estimation of pseudocapacitance contribution; and (f) the contribution of pseudocapacitive effects in the total charge storage of the $3 \mathrm{LCVO}-\mathrm{ABR}$. 

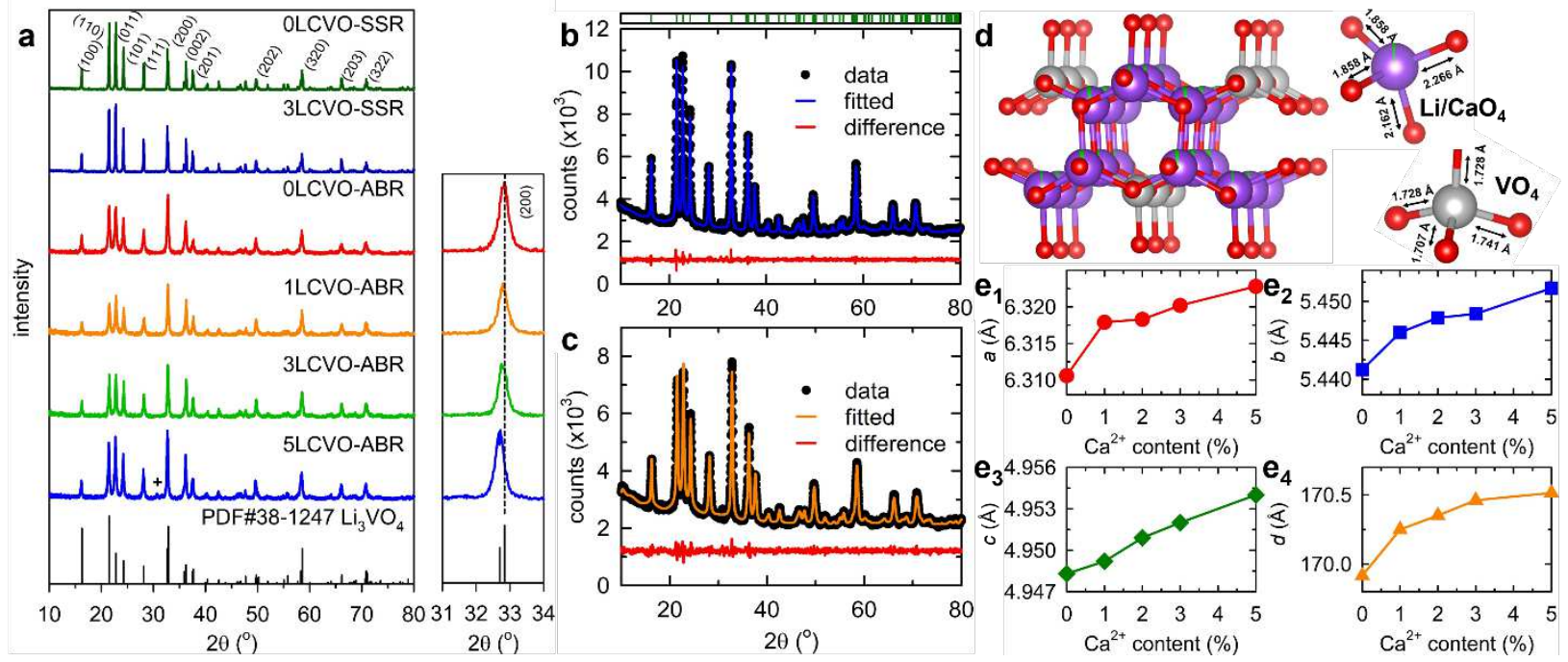

Figure 1. (H.T.H et al.) 

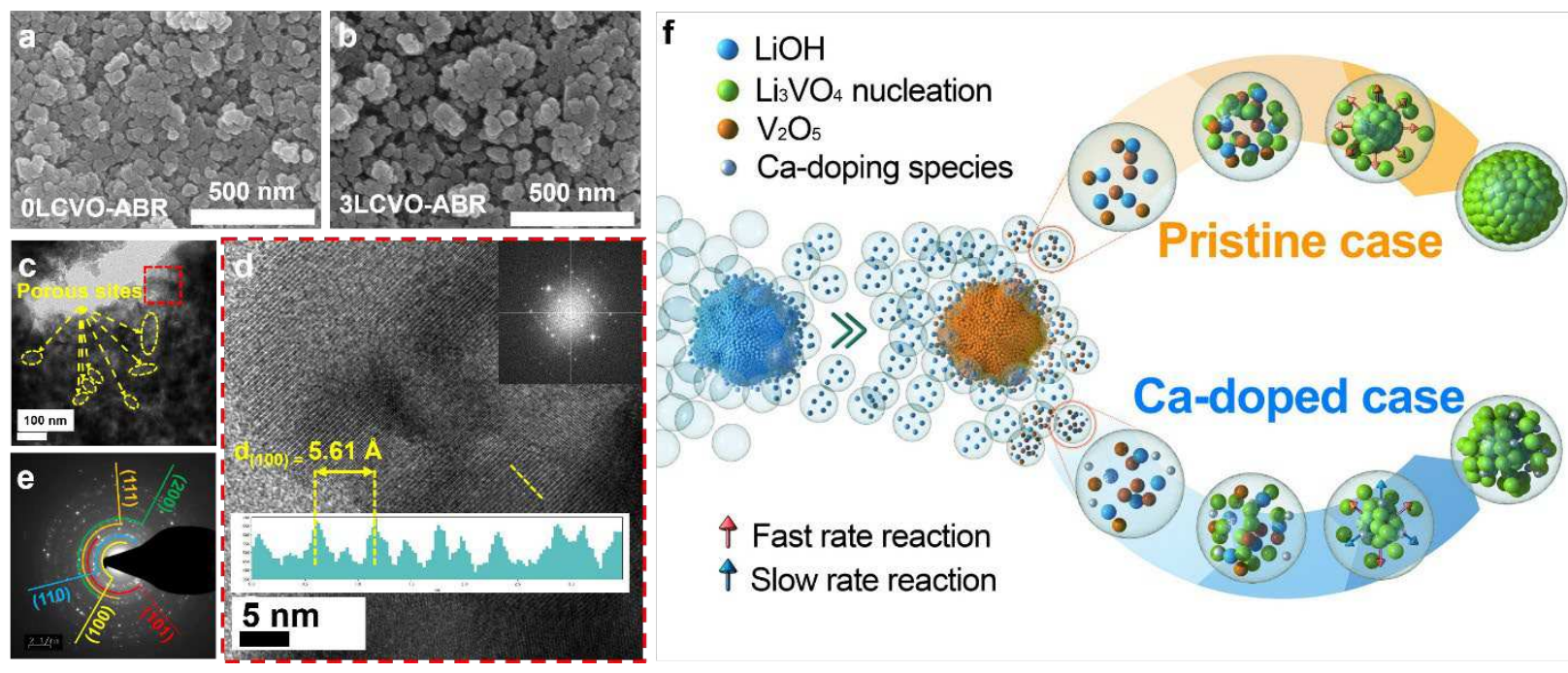
(2)

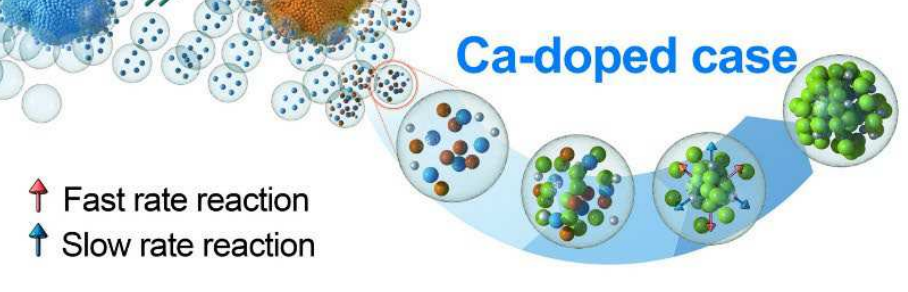

Figure 2. (H.T.H et al.) 


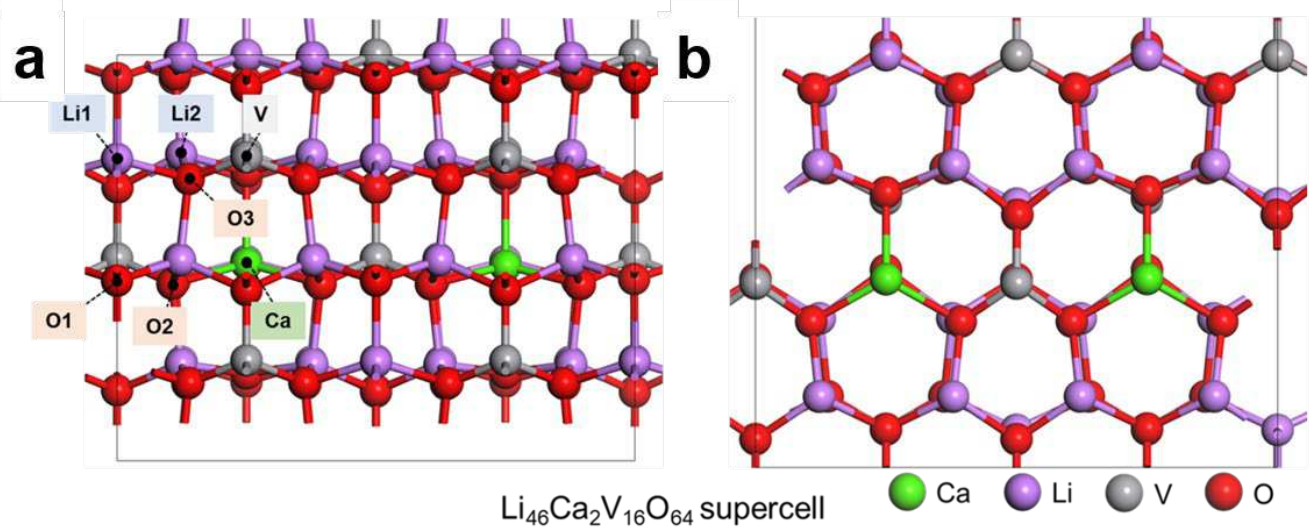

( $\mathrm{Ca}$ atomic ratio $=4.17$ at. $\%$ )
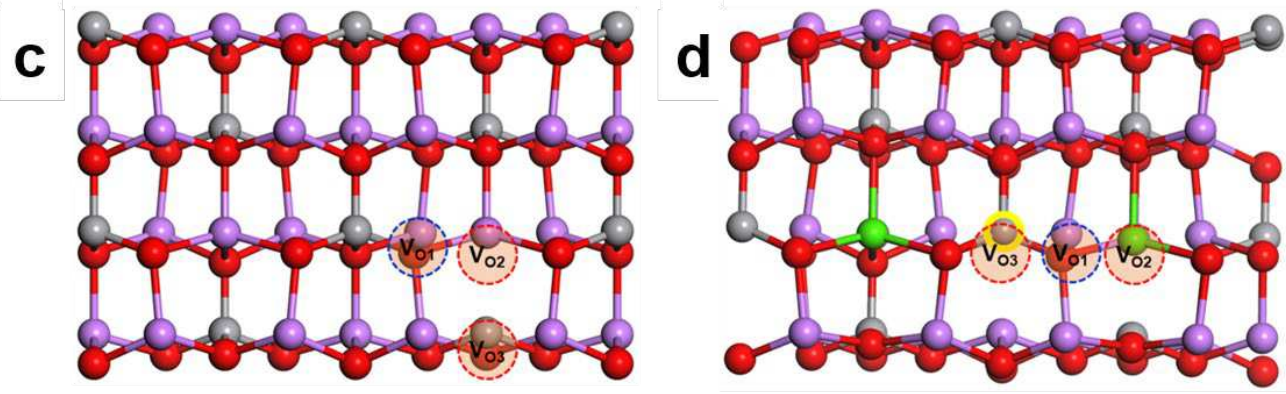

○a $\odot$ li $\odot$ v
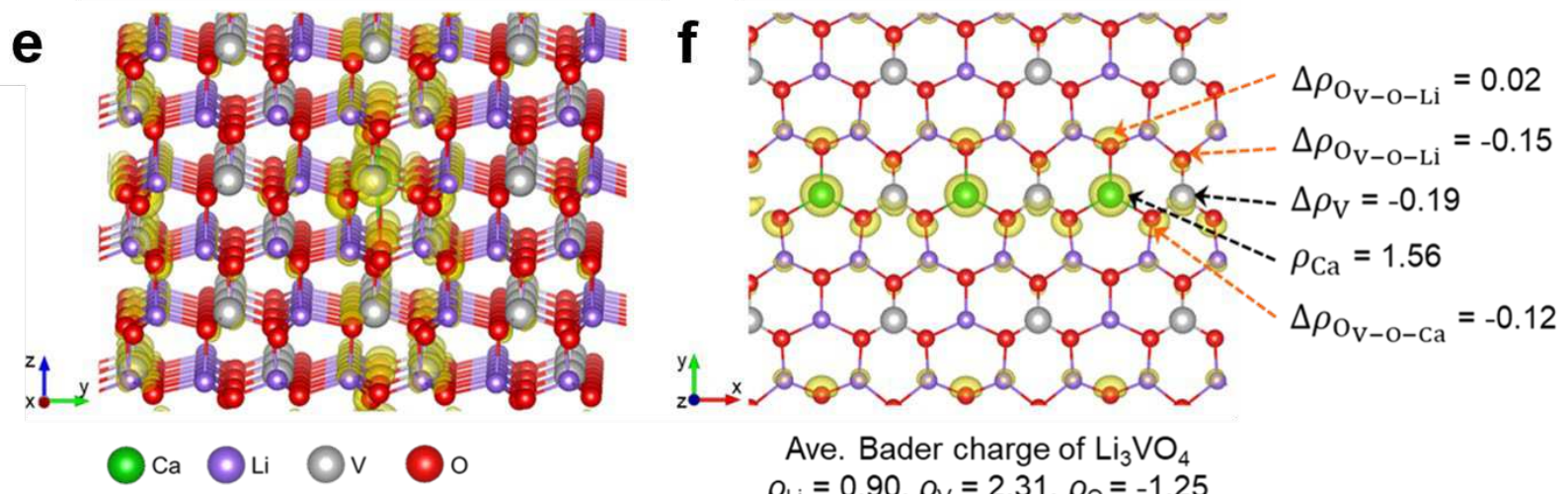

Ave. Bader charge of $\mathrm{Li}_{3} \mathrm{VO}_{4}$ $\rho_{\mathrm{Li}}=0.90, \rho_{V}=2.31, \rho_{\mathrm{O}}=-1.25$

Figure 3. (H.T.H et al.) 

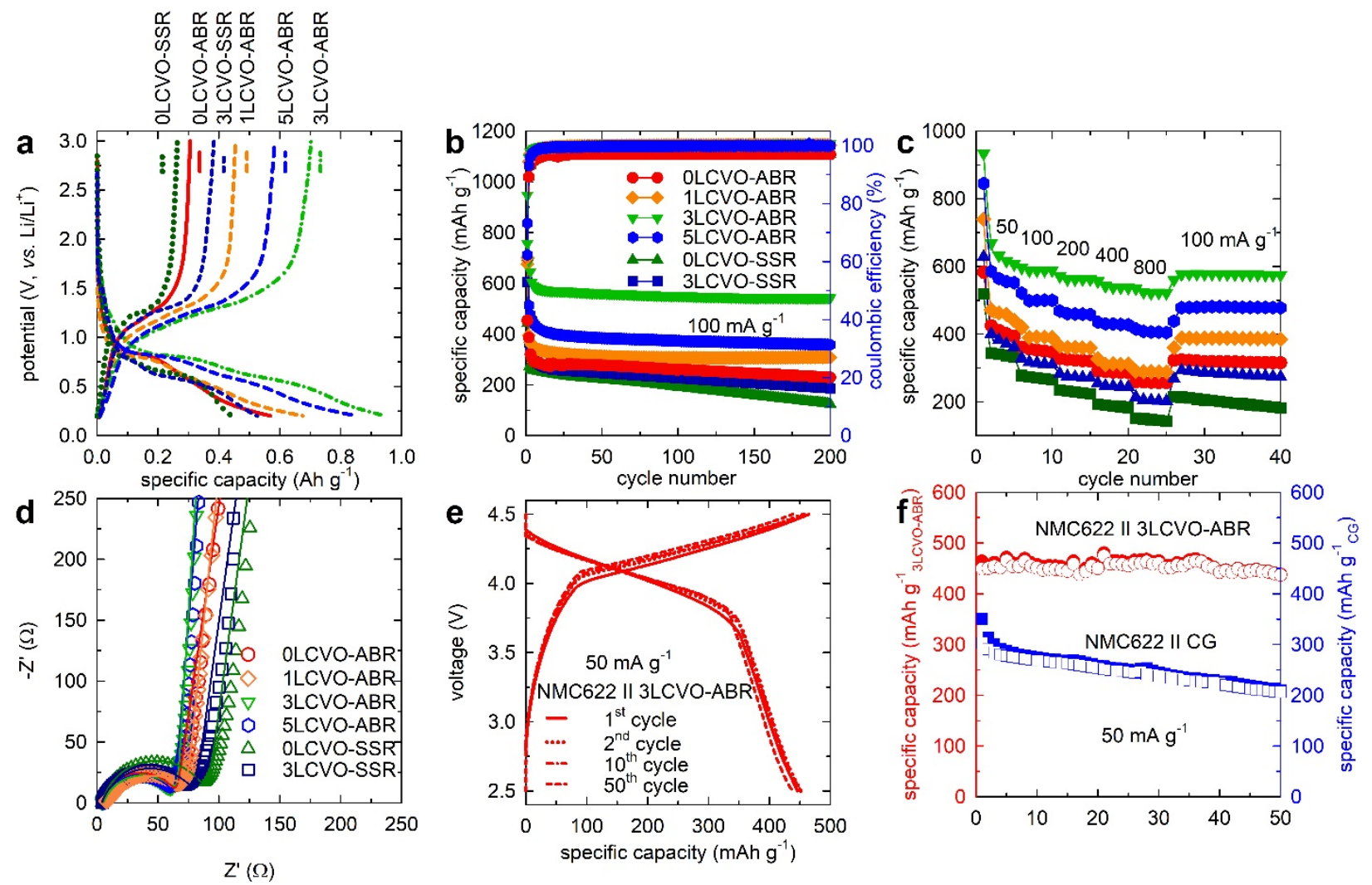

Figure 4. (H.T.H et al.) 

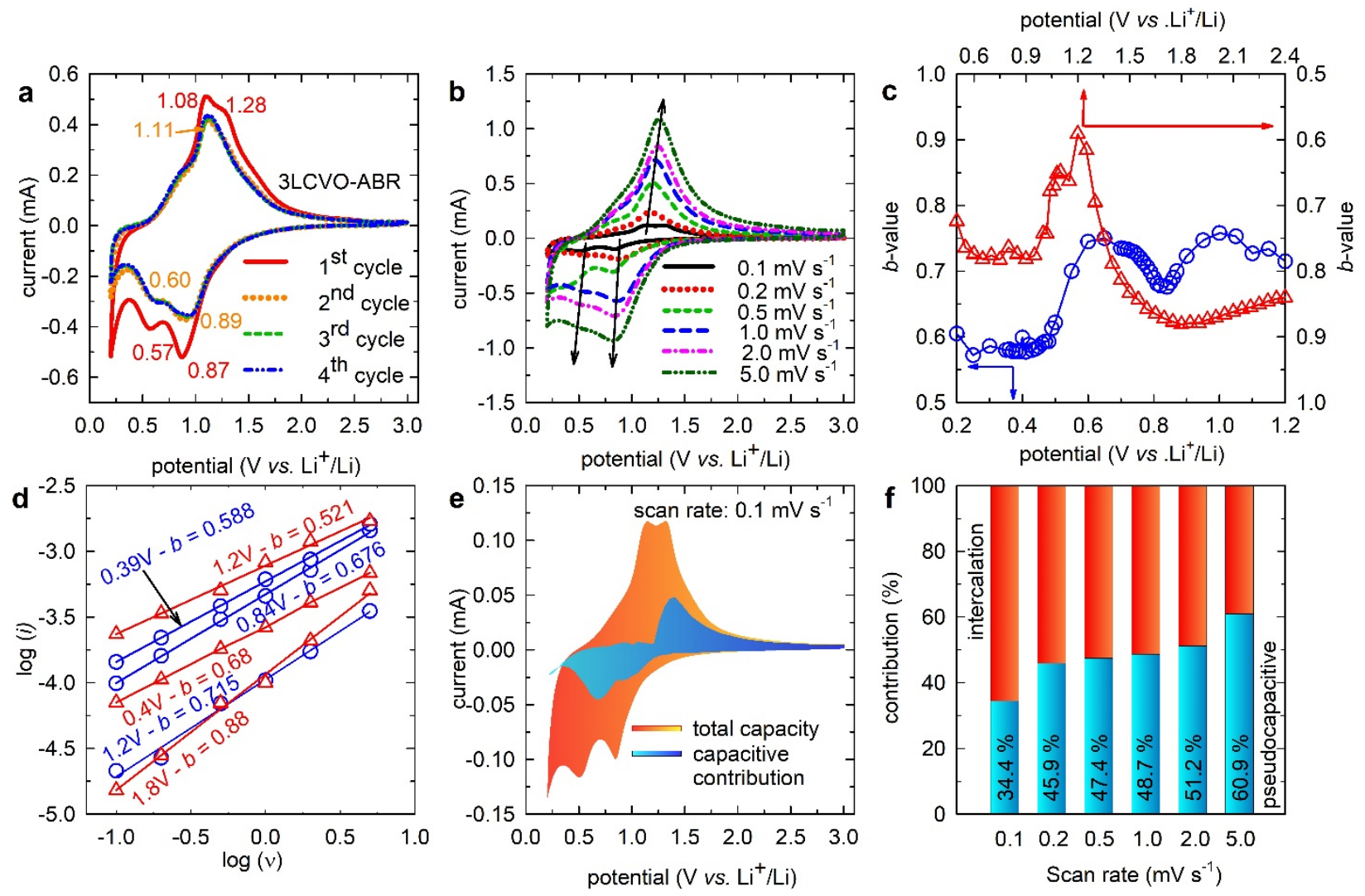

Figure 5. (H.T.H et al.) 


\section{Table list}

Table 1. The refinement XRD information of $0 \mathrm{LCVO}-\mathrm{ABR}$ and 3LCVO-ABR.

\begin{tabular}{|c|c|c|}
\hline sample & 0LCVO-ABR & 3LCVO-ABR \\
\hline symmetry & \multicolumn{2}{|c|}{ orthorhombic } \\
\hline space grpoup & \multicolumn{2}{|c|}{$P m n 2_{1}$} \\
\hline$a(\AA)$ & $6.3106(3)$ & $6.3183(5)$ \\
\hline$b(\AA)$ & $5.4412(2)$ & $5.4479(4)$ \\
\hline$c(\AA)$ & $4.9483(2)$ & $4.9509(2)$ \\
\hline $\mathrm{V}\left(A^{3}\right)$ & $169.916(2)$ & $170.250(3)$ \\
\hline$\chi^{2}$ & 1.724 & 1.639 \\
\hline$R_{w p}(\%)$ & 2.50 & 2.58 \\
\hline$R_{p}(\%)$ & 1.95 & 2.00 \\
\hline
\end{tabular}


Table 2. Structural parameters of $3 \mathrm{LCVO}-\mathrm{ABR}$ as obtained from the combined Rietveld refinement of X-ray. Note: The numbers in parentheses are the estimated standard deviations of the last significant figure.

\begin{tabular}{|c|c|c|c|c|c|c|}
\hline \multirow[b]{2}{*}{ atom } & \multicolumn{3}{|l|}{ Wyckoff } & \multicolumn{3}{|c|}{$100 \times$} \\
\hline & position & $x$ & $y$ & $z$ & $U_{\text {iso }}\left(\AA^{2}\right)$ & $g$ \\
\hline $\mathrm{O} 1$ & $4 b$ & $0.2269(7)$ & $0.6833(12)$ & $0.9098(27)$ & $0.114(2)$ & 1.0 \\
\hline $\mathrm{O} 2$ & $2 a$ & 0.0 & $0.1148(17)$ & $0.9096(29)$ & $0.115(1)$ & 1.0 \\
\hline $\mathrm{O} 3$ & $2 a$ & $1 / 2$ & $0.1801(18)$ & $0.849(4)$ & $0.372(1)$ & 1.0 \\
\hline Li1 & $4 b$ & $0.2461(2)$ & $0.3737(5)$ & $0.9496(8)$ & $0.556(3)$ & 0.99 \\
\hline Li2 & $2 a$ & $1 / 2$ & $0.8830(8)$ & $0.9707(6)$ & $0.155(2)$ & 0.965 \\
\hline V1 & $2 a$ & 0.0 & $0.8330(5)$ & $0.0134(5)$ & $0.951(5)$ & 1.0 \\
\hline $\mathrm{Ca} 1$ & $4 b$ & $0.2461(2)$ & 0.373735 & $0.9496(8)$ & $0.900(1)$ & 0.025 \\
\hline $\mathrm{Ca} 2$ & $2 a$ & $1 / 2$ & $0.8830(8)$ & $0.9707(6)$ & $0.800(2)$ & 0.03 \\
\hline
\end{tabular}


Table 3. Calculation of BET surface area.

\begin{tabular}{ccccc}
\hline \multirow{2}{*}{$\begin{array}{c}\text { Sample } \\
\text { BET linear plot }\end{array}$} & $\begin{array}{c}\text { total surface area } \\
\left(\mathrm{m}^{2} \cdot \mathrm{g}^{-1}\right)\end{array}$ & $\begin{array}{c}\text { total pore } \\
\text { external surface }\end{array}$ & $\begin{array}{c}\text { volume } \\
\left(\mathrm{m}^{2} \cdot \mathrm{g}^{-1}\right)\end{array}$ \\
\hline OLCVO-SSR & $y=28.36 x+0.280$ & 0.152 & 0.1433 & 0.00129 \\
0LCVO-ABR & $y=3.07 x+0.042$ & 1.400 & 1.3100 & 0.01037 \\
3LCVO-SSR & $y=4.26 x+0.023$ & 1.024 & 0.9914 & 0.01136 \\
3LCVO-ABR & $y=0.96 x+0.005$ & 4.484 & 4.0860 & 0.05519 \\
3LMVO-ABR & $y=0.62 x+0.004$ & 6.963 & 6.1260 & 0.07040 \\
\hline
\end{tabular}


Table 4. EIS Charge transfer resistances, linear relation of $Z^{\prime}$ versus $\omega^{-1 / 2}$, and lithium-ion diffusion coefficients of the samples.

\begin{tabular}{ccc}
\hline samples & $\sigma\left(\Omega \cdot \mathrm{s}^{-0.5}\right)$ & $\mathrm{D}_{\mathrm{Li}^{+}}\left(\mathrm{cm}^{2} \cdot \mathrm{s}^{-1}\right)$ \\
\hline 0LCVO-SSR & 69.206 & $6.4 \times 10^{-11}$ \\
OLCVO-ABR & 41.368 & $1.07 \times 10^{-10}$ \\
1LCVO-ABR & 101.397 & $4.4 \times 10^{-11}$ \\
5LCVO-ABR & 41.057 & $1.08 \times 10^{-10}$ \\
3LCVO-ABR & 46.729 & $9.4 \times 10^{-11}$ \\
3LCVO-SSR & 111.900 & $3.9 \times 10^{-11}$ \\
\hline
\end{tabular}


Table 5. The voltage differences between the oxidation and reduction peaks of the 0LCVO-ABR and 3LCVO-ABR.

\begin{tabular}{ccccccc}
\hline sample & cycle & $\varphi_{\mathrm{o}}(\mathrm{V})$ & $\varphi_{\mathrm{r}_{1}}(\mathrm{~V})$ & $\varphi_{\mathrm{r}_{2}}(\mathrm{~V})$ & $\Delta \varphi_{\mathrm{r}_{1}}(\mathrm{~V})$ & $\Delta \varphi_{\mathrm{r}_{2}}(\mathrm{~V})$ \\
\hline 0LCVO-ABR & $2^{\text {nd }}$ & 1.17 & 0.50 & 0.86 & 0.67 & 0.31 \\
& $3^{\text {rd }}$ & 1.15 & 0.51 & 0.85 & 0.64 & 0.30 \\
& $4^{\text {th }}$ & 1.12 & 0.52 & 0.85 & 0.60 & 0.27 \\
3LCVO-ABR & $2^{\text {nd }}$ & 1.11 & 0.60 & 0.89 & 0.51 & 0.22 \\
& $3^{\text {rd }}$ & 1.10 & 0.61 & 0.91 & 0.49 & 0.19 \\
& $4^{\text {th }}$ & 1.09 & 0.62 & 0.92 & 0.47 & 0.17 \\
\hline
\end{tabular}




\section{Figures}
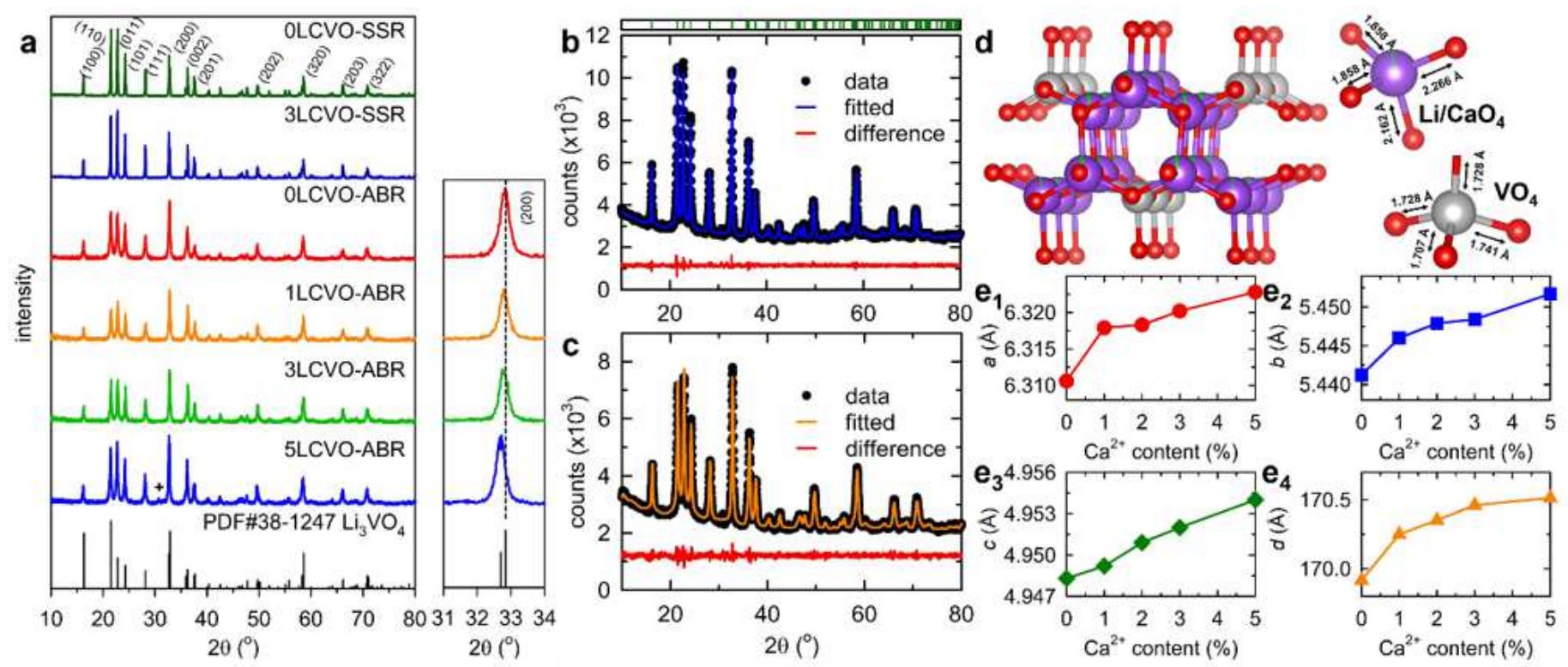

Figure 1

(a) XRD pattern of XLCVO-ABR and -SSR $(x=0,1,3,5)$ (inset: expansion of XRD pattern at $2 \theta=31$ 340); Riveld refinement based on HR-XRD of (b) OLCVO-ABR and (c) 3LCVO-ABR; (d) Crystal structure of Ca-doped Li3VO4 at 3\% of dopant: lithium, vanadium and oxygen atoms were presented by purple, grey and red ball while Ca occupancy was presented by green contribution; dependence of lattice parameters (e1) a, (e2) b, (e3) c and (e4) unit cell volume on content of Ca-dopant.
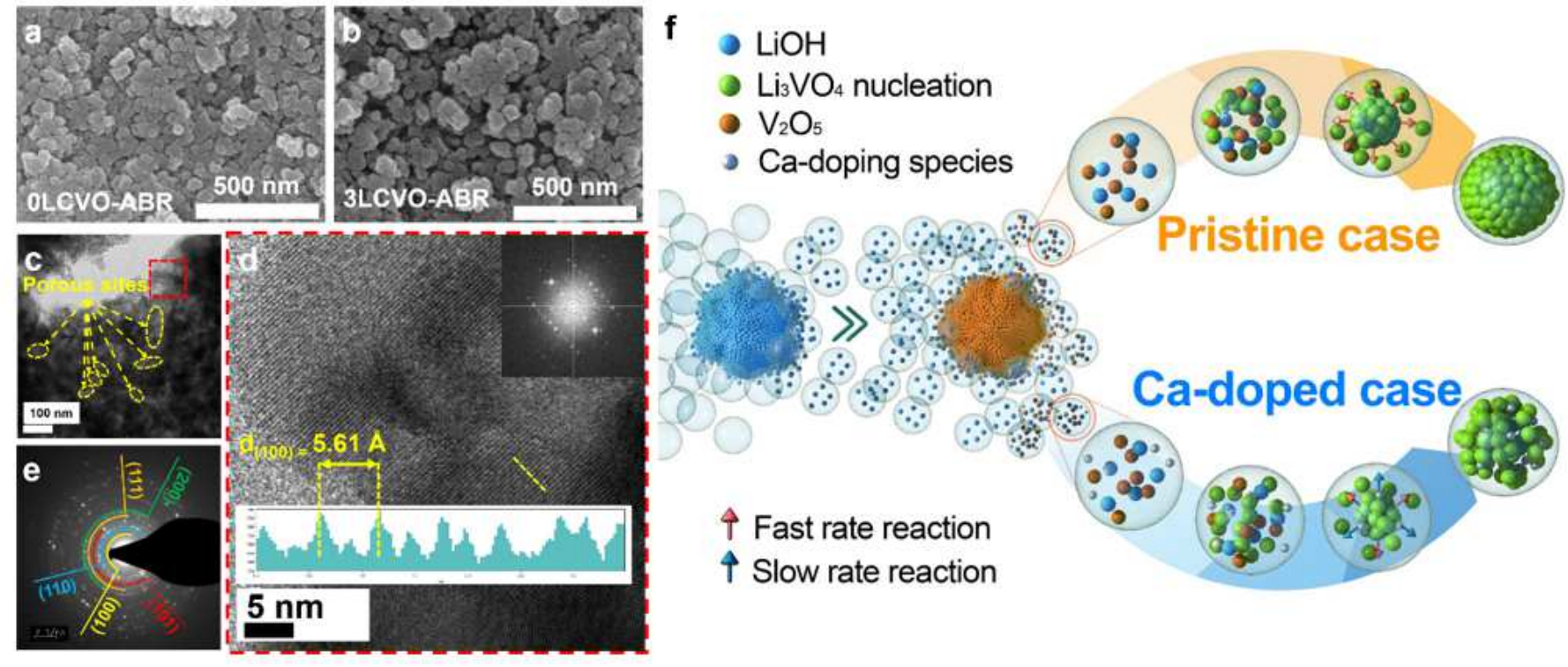

Figure 2 
SEM images of (a) OLCVO-ABR and (b) 3LCVO-ABR; (c) TEM; (d) HR-TEM images and (e) SAED pattern of 3 LCVO-ABR, the FFT image for square inset and the yellow line profile for rectangle inset; ( $f$ ) the proposal mechanism of ABR process and the effect of Ca-doping on the morphology modification of 3LCVO-ABR.

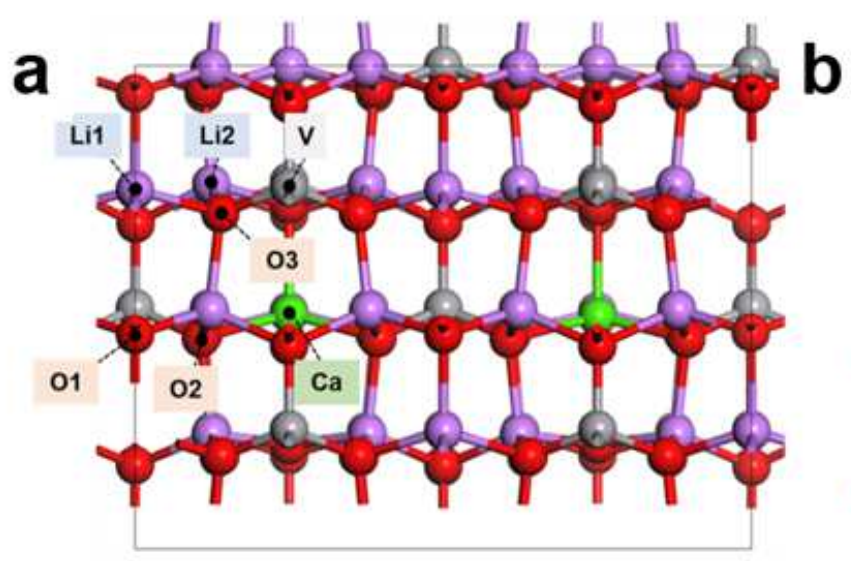

$\mathrm{Li}_{46} \mathrm{Ca}_{2} \mathrm{~V}_{16} \mathrm{O}_{64}$ supercell

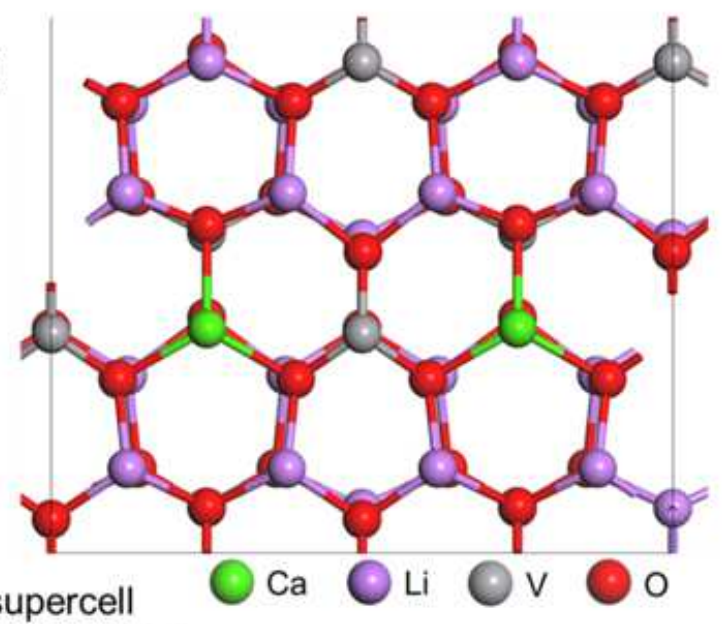

$(\mathrm{Ca}$ atomic ratio $=4.17$ at. $\%)$
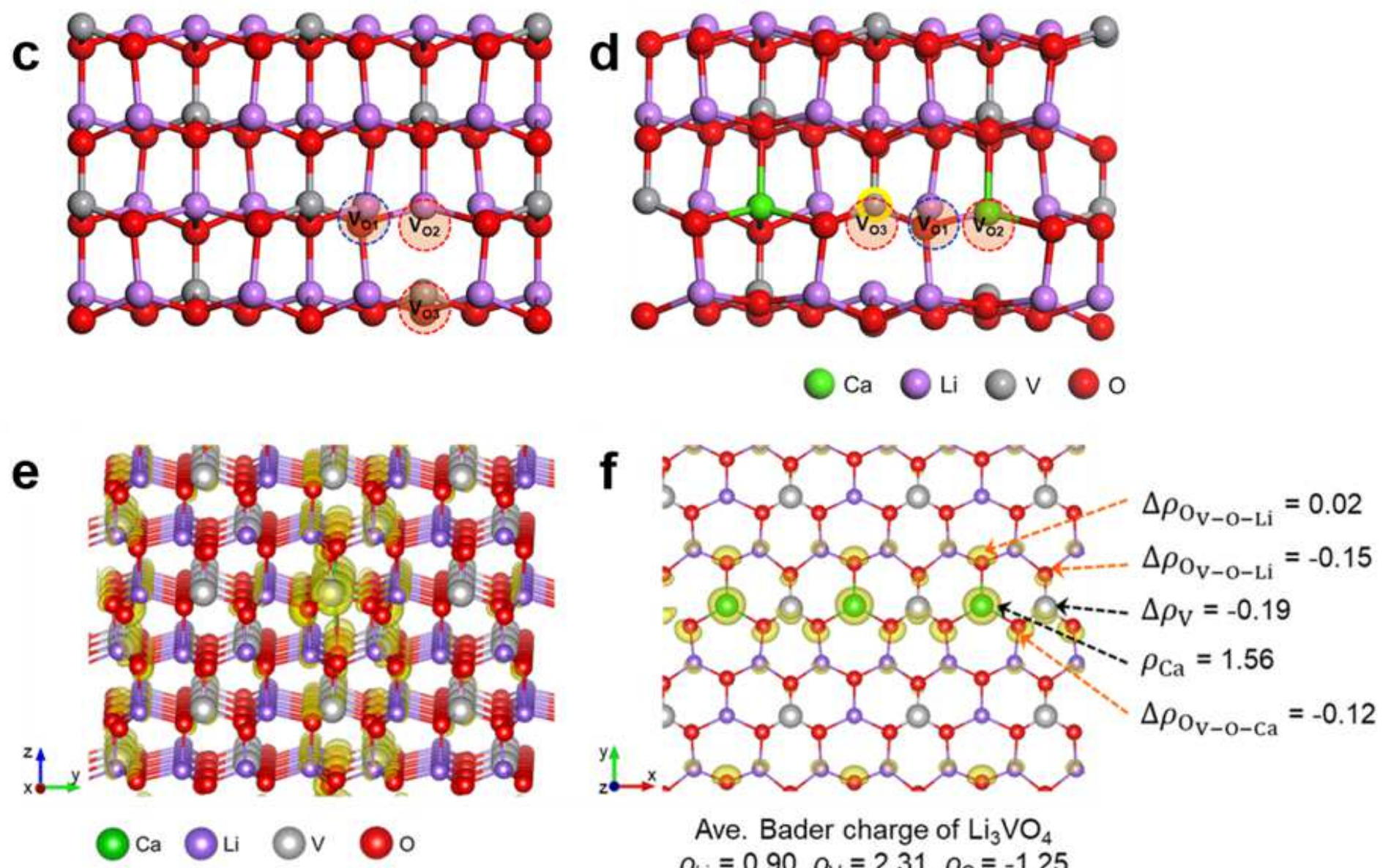

Ave. Bader charge of $\mathrm{Li}_{3} \mathrm{VO}_{4}$ $\rho_{\mathrm{Li}}=0.90, \rho_{\mathrm{V}}=2.31, \rho_{\mathrm{O}}=-1.25$

Figure 3

Morphology of the Li46Ca2V16064 supercell via (a) (010), and (b) (001) plane direction; location of oxygen species used for Evac calculation: (c) Li48V16064 and (d) Li46Ca2V16064. Electron density analysis results. (e) The electron density difference map ( $\rho=0.05$ e/Å3) estimated by abstracting the 
electron density of Li48V16064 from that of Li46Ca2V16064. The yellow highlighted shades present at which extra electrons are localized. (f) The sliced single atomic layer of Li46Ca2V16064 involving the Ca dopants. The electron charge density map and the Bader charge analysis results are accordingly presented. The $\mathbb{Q}$ denotes the Bader charge difference. The ions with negative $\mathbb{Z} \mathbb{Z}$ are enriched with extra electrons.
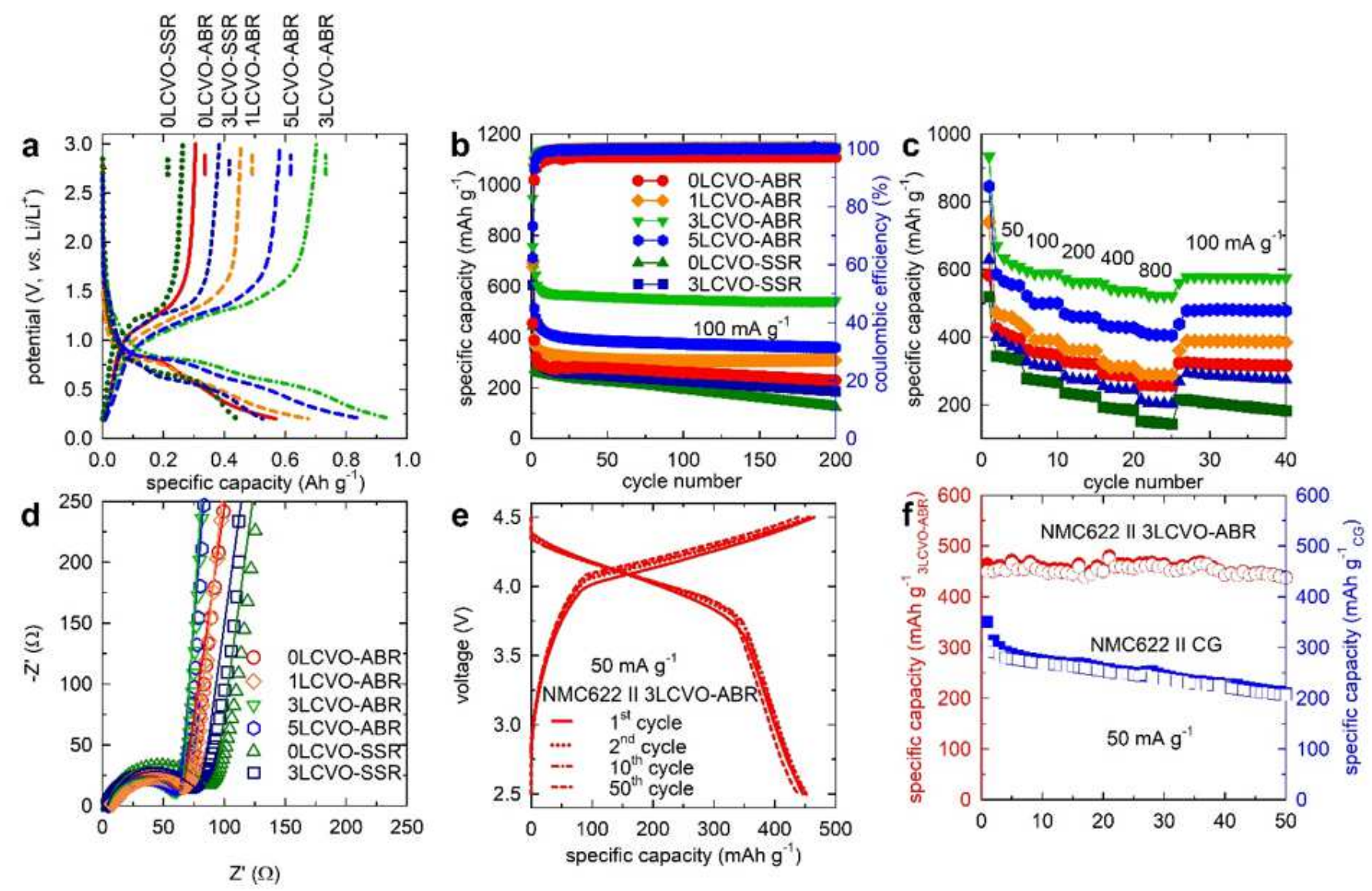

\section{Figure 4}

(a) the first galvanostatic charge-discharge curves (b) cycling performance and (c) c-rate behavior (d) EIS fitting analysis of xLCVO-ABR and -SSR $(x=0,1,3,5)$; (e) galvanostatic charge-discharge curve and ( $f$ ) cycling performance of full-cell of NMC622 cathode and 3LCVO-ABR anode or CG. 
potential ( $\mathrm{V}$ vs $\left.. \mathrm{Li}^{+} / \mathrm{Li}\right)$
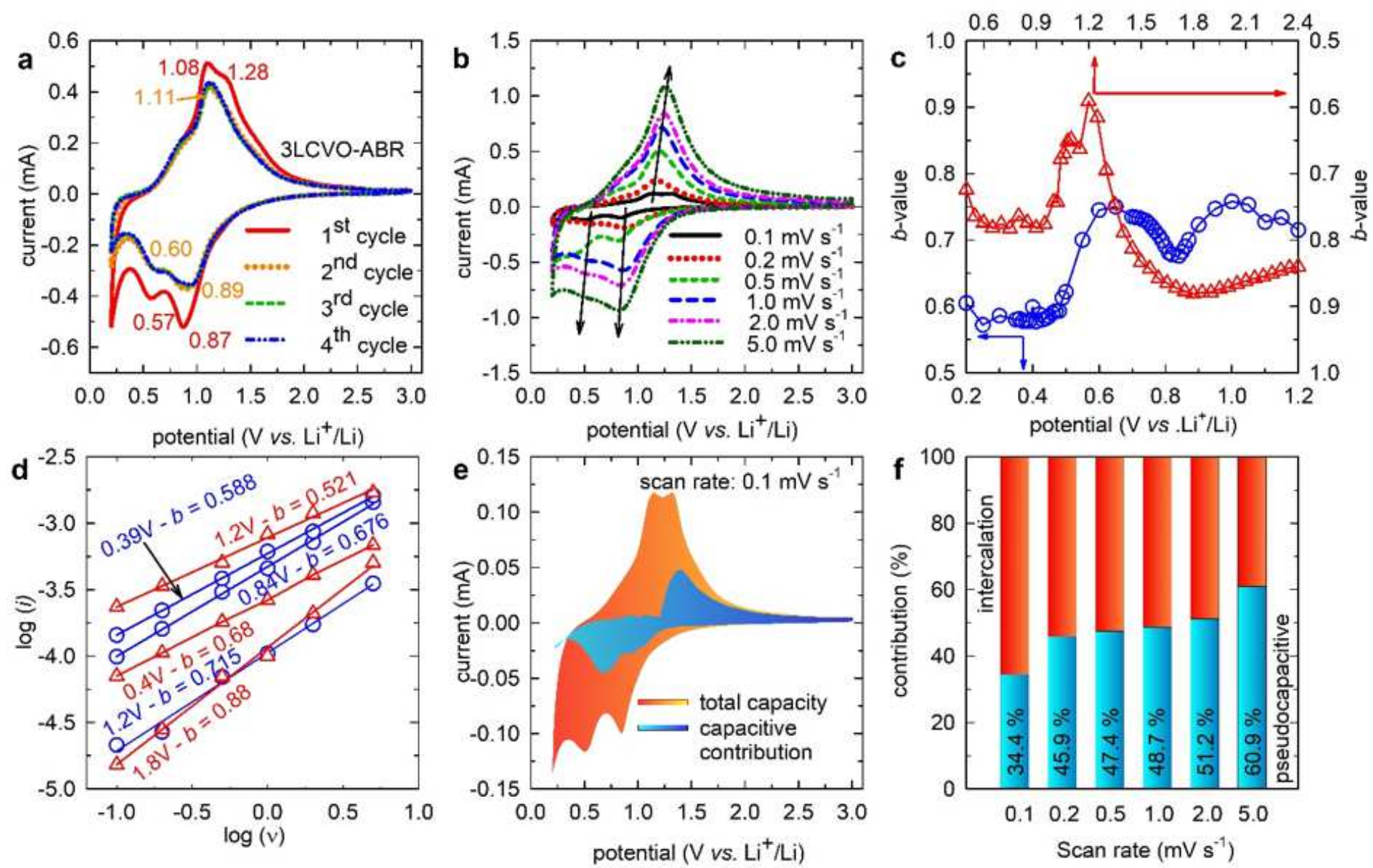

Figure 5

(a) CV of 3LCVO-ABR; (b) CV of 3LCVO-ABR at various scan rate $\mathrm{n}=0.1-5.0 \mathrm{mV} 囚 \mathrm{~s}-1$; (c) dependence of b-value on potential in range of cathodic (red color) and anodic (blue color) peaks; (d) linear fitting of $\log (i)$ vs. $\log ()$ for determination of b-value; (e) pictorial estimation of pseudocapacitance contribution; and (f) the contribution of pseudocapacitive effects in the total charge storage of the 3LCVO-ABR.

\section{Supplementary Files}

This is a list of supplementary files associated with this preprint. Click to download.

- 20200916xLCVOABRforNatCommSI.docx 